\title{
Accuracy control for roll and sheet processed printed electronics on flexible plastic substrates
}

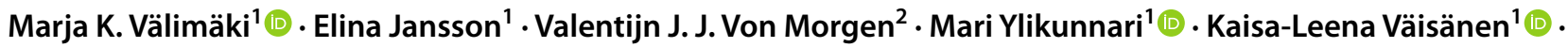 \\ Pekka Ontero ${ }^{1} \cdot$ Minna Kehusmaa ${ }^{1} \cdot$ Pentti Korhonen ${ }^{1} \cdot$ Thomas M. Kraft $^{1}$ (i)
}

Received: 18 June 2021 / Accepted: 7 January 2022 / Published online: 20 January 2022

(c) The Author(s) 2022

\begin{abstract}
For the first time, the necessity to thermally pre-treat ubiquitously used PET substrates for printed electronics, to improve dimensional stability during manufacturing, is clearly defined. The experimental results have proven this phenomenon for both roll-to-roll (R2R) and sheet-to-sheet (S2S) processing of printed electronics. The next generation of electronics manufacturing has pushed the boundaries for low-cost, flexible, printed, and mass produced electronic components and systems. A driving force, and enabling production method, are the R2R printing presses. However, to produce electronics with increasing complexity and high yield in volume production, one must have a highly accurate process. In this article, $\mathrm{R} 2 \mathrm{R}$ processing accuracy of printed electronics is evaluated from the point of dimensional accuracy of the flexible polyester substrate (DuPont Teijin Films' PET Melinex ST504 with and without indium tin oxide, Melinex ST506, and Melinex PCS), precision of printing, and accuracy of layer-to-layer registration with stages that involve tension and elevated temperatures. This study has confirmed that dimensional changes during R2R processing will occur only in the first processing stage and that if a thermal pre-treatment run for the substrate is made-at identical temperature and tension of the processing stagethere is improved stability originating from a new-level strain in the crystalline PET film structure and freezing it in at the tensions and temperatures it is exposed to (i.e. $1400 \mu \mathrm{m}$ machine direction stretching reduced to $8 \mu \mathrm{m}$ ). Furthermore, it is explained how the dimensional accuracy can be improved and reproducibly maintained in multilayer printing of electronics devices such as organic photovoltaics (OPV). These devices provide a valuable baseline of how the layer-to-layer alignment accuracy plays a crucial role in fully printed electronics devices, which lessons can be applied in all aspects of this field including hybrid systems and system fabrication involving multiple processing methods.
\end{abstract}

Keywords Printed electronics $\cdot$ Flexible electronics $\cdot$ Plastic stability $\cdot$ R2R processing

\section{Introduction}

Electronics design and manufacturing have evolved significantly over the past decades and advanced with opportunities provided by printed electronics enabling technologies. Moreover, there is a strong need for high yield and accurate $\mathrm{R} 2 \mathrm{R}$ processes as they can be used in the volume manufacturing of various multilayer devices such as solar cells, supercapacitors and batteries, transistors and flexible hybrid electronics

Marja K. Välimäki

marja.valimaki@vtt.fi

1 VTT Technical Research Centre of Finland, Kaitoväylä 1, P.O. Box 1100, FI-90571 Oulu, Finland

2 DuPont Teijin Films UK Ltd, The Wilton Centre, Redcar TS10 4RF, UK
(FHE), and even double-sided structures [1-11]. Although the use of plastics in roll-to-roll (R2R) production of electronics has become rather ubiquitous in this field, few guidelines and quantitative results have been provided to reduce the effects of substrate deformation that occur under standard processing. Importantly, layer-to-layer alignment accuracy sets a key requirement for printed electronics applications where any deviations in the positioning of the layers impair the device performance and increases performance variations among devices. This registration accuracy defines the precision of the printed, multilayered pattern. The quality of the printed layer is influenced by the rheology of the ink, the surface properties between the ink and the substrate, the precision provided by the printing cylinder or the screen, and the conditions of the processing $[1,12]$. The registration demands in printed electronics are much stricter than in conventional printing where 
the registration demands are related to the limitations of the human eye and are from $100 \mu \mathrm{m}$ to few millimetres. In printed electronics, the registration demands can be even from $5 \mu \mathrm{m}$ to some tens of micrometres [13-16].

The R2R printing process increases the demands for the registration system which is also relevant for sheet-to-sheet (S2S) printing. Web tension fluctuations cause the main source of the registration errors in $\mathrm{R} 2 \mathrm{R}$ printing due to the thermal disturbances of thermal annealing and variation in web speed. Other factors affecting the registration accuracy are composed of the variation in the rotational speed of the process rollers and printing pressure, structural vibrations of the printing press, substrate deformations under web tension, misalignment of the registration marks on the printing tools, accuracy of the registration system and printing press, eccentricity of the printing rollers, and registration mark deformations, i.e. print quality. In R2R printing, the registration errors in machine direction (MD) are greater than the errors in transverse direction (TD) due to the fact that the web tension plays a major role in the printing direction. The reduction in the web tension fluctuations can improve the $\mathrm{MD}$ registration significantly. Furthermore, when electronic structures are printed using heat-curable inks and pastes, the printing process requires thermal treatment with heat. Printed electronics requires significantly higher annealing temperatures and duration compared to conventional printing that can further increase the substrate deformations and registration fluctuations. [13-17] Printing technologies enable direct patterning of desired two-dimensional features in a high-throughput R2R process; however multilayer printing requirements set demands for registration and material interactions [2,3]. There is a fine balance between the need for stable, non-deformable substrates during processing to ensure high registration accuracy for printed electronics, and the desired properties for applications such as flexibility, weight, conformability, optical transparency, environmental sustainability, and biodegradability which implies that more research evidence is needed to optimize processing [1,18-21].

Polymer films are reasonably low cost for electronics and can have positive features such as relatively high stiffness, optical transparency, dimensional stability, low surface roughness, and resistance against various solvents [12, 18, 19]. Semicrystalline polyethylene terephthalate (PET) and polyethylene naphthalate (PEN) have been the most commonly employed substrate materials in printed electronics. Among amorphous polymer films, polycarbonate (PC) and polyethersulphone (PES) can exhibit high optical transparency but the resistance to various solvents is limited; however, polyimide (PI), which absorbs in the visible spectrum, has excellent thermal, chemical, and mechanical stability [12, 18, 19, 22]. The deep colour and low transparency have been the limiting factors of PI thus accelerating the development of colourless and transparent PI films [22].
The processing of heat-stabilized PET involves MD and TD stretching of the film and heat setting at elevated temperature. As a result, a semicrystalline microstructure exhibits improved strength, stiffness, and thermal stability [18]. The PET film is typically manufactured either from a solid polymer chip or directly from polymerization. From polymer chip, the material is melted in an extruder which consists of a screw(s) in a barrel that melts the chip by friction and heat. This melt emerges from a slot and is cooled on a water-chilled drum to form an amorphous unoriented sheet. To add strength to the sheet, the molecules are then oriented and aligned into the plane of the sheet by heating and stretching by typically three to four times in both directions either sequentially or simultaneously. Further heating causes the sheet to partially crystallize which helps lock in this molecular orientation into the plane of the sheet, adding to the dimensional stability of the product (Table 1). Further processing, either during manufacture of the product or via subsequent processing, can further improve dimensional stability [23, 24].

Although a standard biaxially oriented PET film has a high level of dimensional stability at elevated temperatures, a small amount of the initial stretch will still be released if the film is heated above its glass transition temperature ( $\mathrm{Tg})$, with a corresponding reduction in length. For an unrestrained sheet (i.e. zero tension), this property of length loss is called shrinkage and usually measured in perpendicular directions at either $150{ }^{\circ} \mathrm{C}$ or $190{ }^{\circ} \mathrm{C}$ and is typically ranging from $0 \%$ to $3 \%$. The shrinkage is temperature-dependent, and releases some of the original stretch imparted during the manufacture of the PET film. For films which require additional dimensional stability when used at elevated temperatures, the PET sheet can be further processed at low tension at a specific high temperature which allows this shrinkage process to take place in a controlled manner. A film prepared in this way will, in subsequent use at wider temperature range, exhibits almost no further shrinkage, again when unrestrained (at zero tension). The film such as this is termed "stabilized" for use up to this specific temperature $[18,26]$.

In this article, we examine and quantify the $\mathrm{R} 2 \mathrm{R}$ processing accuracy in printed electronics from the point of dimensional accuracy of substrate, precision of printing, and accuracy of layer-to-layer registration. We also present how the dimensional accuracy can be improved and reproducibly maintained in multilayer printing of electronics devices employing an organic photovoltaic (OPV) as a case study.

\section{Methods}

Dimensional accuracy of substrate in R2R process Heat stabilized PET (HS-PET) Melinex ST506, PCS, and ST504 were received from DuPont Teijin Films LP (Chester, VA, US). Indium tin oxide (ITO)-coated ST504 (OC-50) was 
purchased from Eastman Flexvue (Eastman Chemical Company, Kingsport, USA). The substrate dimensional MD changes were assessed before and after processing using marks that were mechanically die-cut with Alpha Reel (Alpha Converting Equipment Ltd, Bedford, UK) and measured off-line using ESM-25-50/1000 electronic scale (Prometra GmbH Mess- und Prüftechnik, Balzers, Liechtenstein). The distance of prepared die-cut marks was measured before and after R2R treatment at zero tension, and the layout for die-cutting is presented in Supplementary data S1. R2R thermal treatment of the substrates was prepared with the MAXI R2R printing machine (Coatema Coating Machinery GmbH, Dormagen, Germany) and using its four hot air box ovens. First and second R2R thermal treatments of the substrates were carried out at $140{ }^{\circ} \mathrm{C}$ using $300 \mathrm{~mm}$ wide web, $80 \mathrm{~N}$ outfeed tension, and $2 \mathrm{~m} / \mathrm{min}$ processing speed. The thermal treatment time per treatment cycle was $7 \mathrm{~min}$. The total length of four box ovens was $14 \mathrm{~m}$, and the length of the web path from the unwinder to the rewinder was $60 \mathrm{~m}$.

Dimensional accuracy of substrate in S2S process Melinex ST506 from DuPont Teijin Films LP (Chester, VA, USA). First and second S2S thermal treatment of ST506 was carried out with hot air using A5-sized substrates, and a conventional laboratory oven (UNE 700, Memmert GmbH + Co. KG, Schwabach, Germany). Accuracy of temperature during the thermal treatment was confirmed by thermocouple (80PK-1, Fluke, Everett, WA, USA). The dimensional MD and TD changes were assessed before and after S2S thermal treatments with the help of a lattice pattern that was drawn on each sample prior to the first S2S treatment cycle, and measured with a Smartscope OGP250 microscope (Optical Gaging Products, Rochester, NY, USA). For the comparison between dimensional stability studies, R2R and S2S experiments were executed at $140{ }^{\circ} \mathrm{C}$. Additionally, 150 ${ }^{\circ} \mathrm{C}$ was selected for $\mathrm{S} 2 \mathrm{~S}$ to have a reference point to the manufacturer (DuPont Teijin Films Ltd.) supplied product data sheet of PET.

\section{Alignment of multilayered printed architectures R2R print-} ing trial runs were done with the MAXI printing line which has four interchangeable printing units and an automatic camera-based registration system. The possible printing methods include gravure, rotary screen printing, and flexography. The registration limits of the MAXI printing press were first determined using all the three printing methods in the first printing unit. Commercially available graphics inks were printed onto a $125-\mu \mathrm{m}$-thick HS-PET (Melinex ST506) substrate. The substrate was not thermally pre-treated before the registration trials. A layer with reference registration marks was first printed onto the substrate using the first printing unit. After this, another ink layer was overprinted and automatically registered to the reference marks using the same printing unit. Two roll-to-roll (R2R) printing runs at different printing speeds were made using each of the printing methods. The printing speeds were $2 \mathrm{~m} / \mathrm{min}$ and $5 \mathrm{~m} /$ min with rotary screen printing and $5 \mathrm{~m} / \mathrm{min}$ and $10 \mathrm{~m} / \mathrm{min}$ with gravure and flexography. The higher printing speed in gravure and flexography came from the lower ink viscosity. All the deposited layers were thermally treated online in the hot air ovens of MAXI at $100{ }^{\circ} \mathrm{C}$. The total time of thermal annealing was 1.4-7 min depending on the printing speed. The registration data were saved online during the print runs.

S2S registration printing The effect of the thermal pretreatment of the substrate on the registration accuracy was analysed in S2S registration printing trials. The substrate was a $125-\mu \mathrm{m}$-thick HS-PET (Melinex ST506). The substrate was either thermally pre-treated at $130{ }^{\circ} \mathrm{C}$ for $60 \mathrm{~min}$ or left un-treated. An EKRA XH STS screen printer with a camera-based automatic registration system was used to print four ink layers on the top of each other onto the untreated and treated substrate sheets. All the printed layers were thermally treated similarly in a hot air oven at $130^{\circ} \mathrm{C}$ for $30 \mathrm{~min}$. The registration accuracy was measured with a microscope Smartscope OGP250 (Optical Gaging Products, Rochester, NY, USA).

Characterization of PET substrates: Melinex ST506 films were characterized using differential scanning calorimetry (DSC) DSC 6000 (PerkinElmer, Waltham, MA, USA). Haze was characterized using Haze-gard Plus Hazemeter (BYKGardner GmbH, Geretsried, Germany), and the results comprised average of five measurements across each sample.

Fabrication and characterization of printed OPV The inverted OPV module structure comprised five layers that were either printed or patterned in separate R2R process steps. ITO was R2R patterned with Isishape HiperEtch 09S Type 40 paste (Merck \& Co. Inc., Kenilworth, NJ, USA) in a rotary screen process with $200-\mathrm{L}$ (mesh/inch) steel mesh screen (Gallus Ferd. Rüesch AG, St. Gallen, Switzerland) using ROKO R2R printing machine (RK Print Coat Instruments Ltd, Royston, UK) with a printing speed of $1.5 \mathrm{~m} /$ min and etching at $140{ }^{\circ} \mathrm{C}$. The following four layers were printed with MAXI R2R printing machine. Printed layers were aligned with automated regi_star 20 registration system (BST Eltromat International GmbH, Bielefeld, Germany). 5.0\% wt-\% Zinc Oxide (ZnO) N-12/7022 (Avantama AG, Stäfa, Switzerland) and $0.13 \mathrm{~g} / \mathrm{ml}$ blend of regioregular poly(3-hexylthiophene) (P3HT) \#4002-E (Rieke Metals, Lincoln, NE, USA) and [6, 6]-pheny 1C61 butyric acid methyl ester (PCBM) [C60] (Nano-C, Westwood, MA, USA) inks were gravure printed with 120 lines/cm cylinder engravings, printing speed of $8 \mathrm{~m} / \mathrm{min}$, and $\mathrm{ZnO}$ thermally 
treated at $140{ }^{\circ} \mathrm{C}$ and P3HT:PCBM at $120^{\circ} \mathrm{C}$ with a total time of thermal annealing $1.75 \mathrm{~min}$. The R2R plasma process after $\mathrm{ZnO}$ printing was performed with a web speed of $2 \mathrm{~m} / \mathrm{min}$ and an argon-nitrogen mixture with the power of $200 \mathrm{~W}$. poly(3, 4-ethylenedioxythiophene):poly(styrenesulphonate) (PEDOT:PSS) Orgacon EL-P 5015 (Agfa-Gevaert N.V., Mortsel, Belgium) was R2R rotary screen-printed with a Stork rotaplate 215V screen (SPGPrints B.V., Boxmeer, Netherlands), printing speed of $2 \mathrm{~m} / \mathrm{min}$ and thermally treated at $120{ }^{\circ} \mathrm{C}$ with a total time of thermal annealing 7 min. R2R rotary screen printing of XPVS-670 silver paste (PPG Industries Inc., Pittsburgh, PA, USA) was printed with a RVS 275 L steel mesh screen (Gallus Ferd. Rüesch AG, St. Gallen, Switzerland) with printing speed of $2 \mathrm{~m} / \mathrm{min}$ and thermally treated at $120^{\circ} \mathrm{C}$ with a total time of thermal annealing $7 \mathrm{~min}$.

The initial premise for the thermal pre-treatment is that it would take place at the temperature that is either the same, or higher, than the highest processing temperature used during device manufacturing. In OPV fabrication, the highest $\mathrm{R} 2 \mathrm{R}$ processing temperature is $140{ }^{\circ} \mathrm{C}$, and for sheet oven curing, it is $130^{\circ} \mathrm{C}$. For this reason, the substrate used in the $\mathrm{R} 2 \mathrm{R}$ and S2S study was pre-treated at $140{ }^{\circ} \mathrm{C}$. Key information in $\mathrm{S} 2 \mathrm{~S}$ and $\mathrm{R} 2 \mathrm{R}$ processing is presented in Table 2.

The effect of the registration accuracy on the performance of the printed electronics devices was determined with R2R printed OPV modules using MAXI. All the deposited layers were registered to the patterned ITO layer. The OPV current-voltage characteristics were measured with Atlas SolarCellTest 1200 solar simulator (AMETEK Inc., Berwyn, $\mathrm{PA}, \mathrm{USA}$ ) at $100 \mathrm{~mW} / \mathrm{cm}^{2}$ using a calibrated Si-reference cell filtered with a KG5 filter. The measured modules were unencapsulated, and the active area of the printed solar cells was defined by calculating the overlap of ITO and Ag electrodes. The registration accuracy of the OPV layers was measured with a microscope Smartscope OGP250 (Optical Gaging Products, Rochester, NY, USA).

\section{Results and discussion}

In the following subchapters, we present the R2R and S2S processing accuracy for printed electronics by examining the accuracy of the PET substrate, printing techniques and layerto-layer registration. We also present how the dimensional accuracy is improved and further implemented in printed electronics processing by fabricating OPVs on a R2R line.

\subsection{Dimensional accuracy of the PET substrate in the $R 2 R$ process}

The aim of the pilot printing experiment was to define how to control the stability of a PET substrate in the R2R process and to improve the dimensional accuracy in multilayer printing. The dimensional accuracy of HS-PET substrates was evaluated by exposing the substrate materials to the heat and tension of a R2R cycle, and measuring the substrate MD dimensions before and after the processing at ambient temperature and zero tension. With directional (MD or TD) accuracy defined as the dimensional offset in the MD or TD direction in relation to the initial dimensions of the substrate (large deviation results in low accuracy). Figure 1 presents the schematic image of the VTT's pilot printing line (MAXI). In the web process, the substrate roll goes under controlled tension from the unwinder through the web guides and guide rolls, printing and hot air drying units to the rewinder after processing.

During each R2R cycle, DuPont Teijin Films' 300-mm wide and 125- $\mu \mathrm{m}$-thick Melinex ST506 (ST506), 100- $\mu \mathrm{m}$ Melinex PCS (PCS), 125- $\mu$ m Melinex ST504 (ST504) and 125- $\mu \mathrm{m}$ ITO-coated Melinex ST504 substrate (ITO-ST504) were exposed to hot air at $140{ }^{\circ} \mathrm{C}$ and an unwinder-rewinder tension of $80 \mathrm{~N}(267 \mathrm{~N} / \mathrm{m})$. The $140{ }^{\circ} \mathrm{C}$ temperature was selected as this is the maximum processing temperature of the MAXI pilot machine (hot air ovens), and $80 \mathrm{~N}$ is the optimized web tension for the web handling (i.e. not too loose or tight, and avoiding slipping) and processing of $100-125-\mu \mathrm{m}$-thick PET substrate (tension being a substrate dependent condition) in register. With commonly used temperatures for annealing printed inks and pastes for electronic components and systems (i.e. flexible hybrid electronics), it ranges from $100-140{ }^{\circ} \mathrm{C}$; choosing the upper limit provides the clearest guidance for manufacturing exploitation $[2,4,9$, 11]. To ensure reproducibility, the experiment was repeated with two PET ST506 and PCS substrate materials (Series II in Fig. 2).

The obtained results show consistently the PET and ITO-PET substrate MD elongation after being thermally treated in the first cycle, which challenges the layer-tolayer alignment. During the second cycle, MD inaccuracy of the substrate was reduced significantly. Furthermore, ST506 and PCS had the lowest dimensional change in MD resulting in the highest MD accuracy, whereas the ITO-PET showed the largest deviation in MD direction. Table 3 presents the MD accuracy of R2R processed PET substrates.

MD elongation was reduced from $0.357 \%$ to $0.002 \%$ with PET and from $0.206 \%$ to $0.042 \%$ with ITO-PET after the second R2R cycle. This implies that in a $100-\mathrm{mm}$ length of substrate, the MD elongation of PET is decreased from $357 \mu \mathrm{m}$ to $2 \mu \mathrm{m}$ and in the context of a circumference of a printing screen and cylinder $(409.570 \mathrm{~mm})$ from $1460 \mu \mathrm{m}$ to $8 \mu \mathrm{m}$, respectively. This value of $8 \mu \mathrm{m}$ is an acceptable/minor error and easily corrected in automated registration systems. Furthermore, Series II supports high substrate accuracy and processing reproducibility after the 


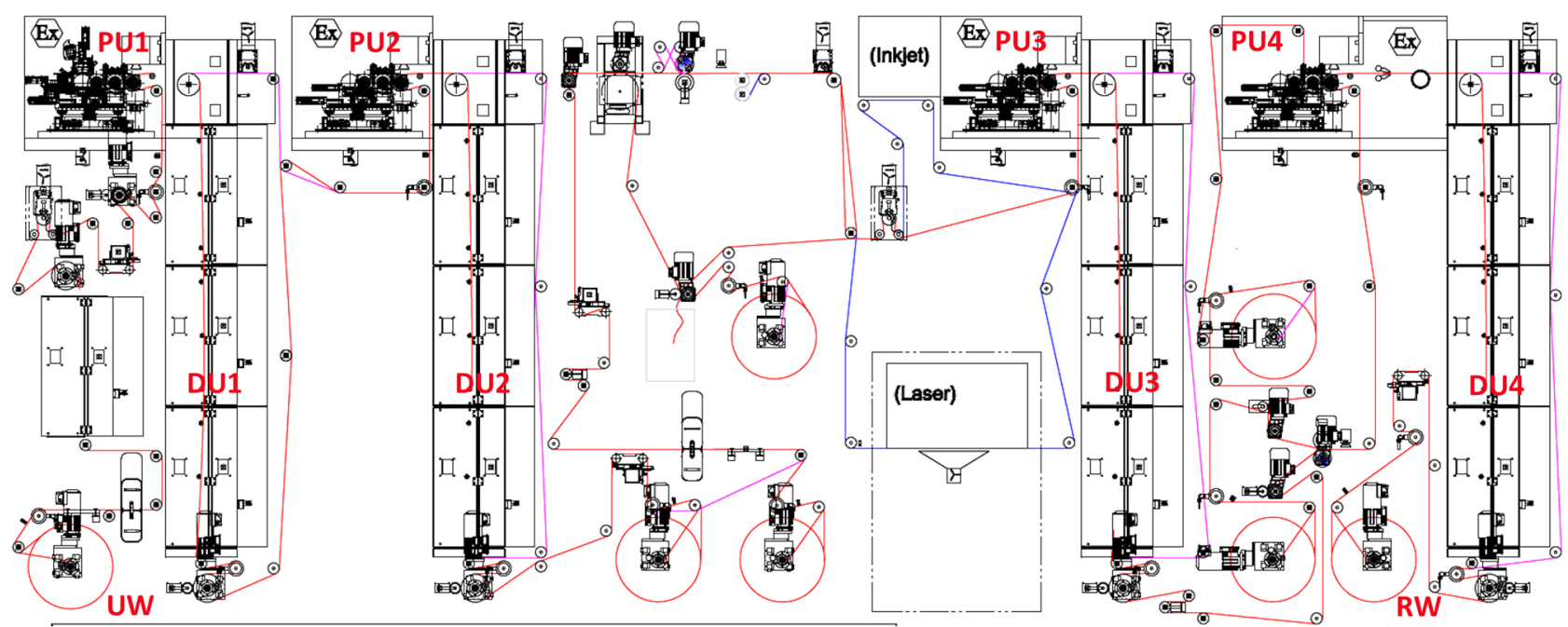

Fig. 1 Schematic image presenting VTT's pilot printing line (MAXI, Coatema Coating Machinery $\mathrm{GmbH}$ ) where path of the substrate from unwinder (UW) to rewinder (RW) is depicted by the red line as it passes through all the printing units (PU) and drying units (DU). Four printing units and four hot air drying units, are marked as PU1-PU4, DU1-DU4. Image is provided by Coatema Coating Machinery GmbH
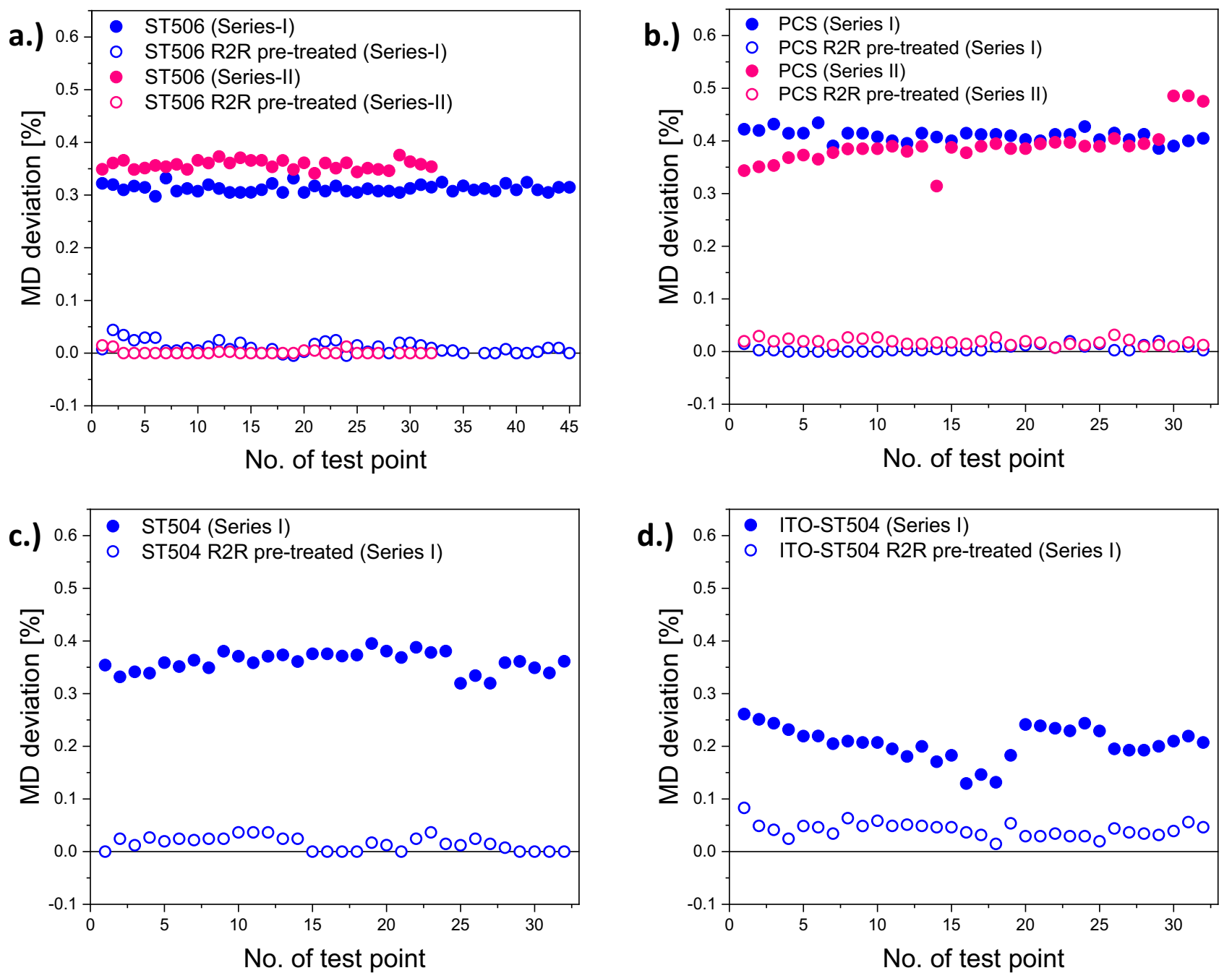

Fig. 2 Sample regions presenting machine direction (MD) accuracy of Series I and II R2R processed HS-PET substrates after R2R first and second $\mathrm{R} 2 \mathrm{R}$ cycle in $\mathrm{R} 2 \mathrm{R}$ pilot process. 
Table 1 Typical machine direction (MD) and transverse direction (TD) shrinkage of DuPont Teijin Films' Melinex® 504 regular (standard) and stabilized, biaxially oriented (BO), BOPET film after thermal exposure of $150{ }^{\circ} \mathrm{C}$ for 30 min under unrestrained conditions [25]

\begin{tabular}{lll}
\hline Film type & $\begin{array}{l}\text { MD } \\
{[\%]}\end{array}$ & $\begin{array}{l}\text { TD } \\
{[\%]}\end{array}$ \\
\hline Standard BOPET & 1.0 & 0.5 \\
Off-line Stabilized BOPET & 0.15 & 0.15 \\
\hline
\end{tabular}

second cycle. With the results clearly showing that the preliminary thermal treatment in the $\mathrm{R} 2 \mathrm{R}$ cycle prior to $\mathrm{R} 2 \mathrm{R}$ printing improves the dimensional accuracy of the PET and ITO-PET substrate.

\subsection{Dimensional accuracy of the PET substrate in $\mathrm{S} 2 \mathrm{~S}$ process}

In laboratory-scale experiments, the MD and transverse direction (TD, substrate width perpendicular to MD) accuracy of ST506 was assessed by thermally treating the substrates in unrestrained conditions and by performing measurements at ambient temperature and zero tension. The sheets of unprocessed and previously $\mathrm{R} 2 \mathrm{R}$ processed substrates were exposed to thermal treatment under hot air at $140{ }^{\circ} \mathrm{C}, 150{ }^{\circ} \mathrm{C}$ and $85^{\circ} \mathrm{C}$ temperatures in a laboratoryscale oven for $30 \mathrm{~min} .140^{\circ} \mathrm{C}$ was selected in order to have the same temperature as in the $R 2 R$ process, $150{ }^{\circ} \mathrm{C}$ to have the same conditions as in products' technical datasheets, and $85^{\circ} \mathrm{C}$ as this is the same temperature used in $85 / 85$ reliability test standards for electronics, such as JESD22-A101D, where the accelerated ageing conditions are comprised of a test temperature of $85{ }^{\circ} \mathrm{C}$ and relative humidity of $85 \%$ $[27,28]$. The $150^{\circ} \mathrm{C}$ hot air treatment was conducted twice, with the substrate elongation/shrinkage being measured after each annealing to detect if the magnitude changes after the first $150{ }^{\circ} \mathrm{C}$ hot air treatment. Table presents the MD and TD accuracy of the untreated PET substrates after S2S processing.
The dimensions of the untreated ST506 substrates changed $-0.097 \%$ in MD and $-0.134 \%$ in TD after being S2S thermally treated for $30 \mathrm{~min}$ at $150{ }^{\circ} \mathrm{C}$ while unrestrained (Table 4). The results corresponded with the product datasheet [25]. Notably, the changes of the second S2S cycle at $150{ }^{\circ} \mathrm{C}$ were only $0.024 \%$ in MD and $-0.013 \%$ in TD. In S2S processing, the thermal pre-treatment of the unstrained substrate improves the dimensional accuracy reducing the changes. Furthermore, the processing temperature decreases from 150 to $140{ }^{\circ} \mathrm{C}$ reduced the substrate shrinking under S2S processing conditions to $-0.038 \%$ (MD) and $-0.006 \%$ (TD) already in the first cycle. The processing at $85{ }^{\circ} \mathrm{C}$ led to dimensional changes that are somewhat similar to the changes obtained at $140{ }^{\circ} \mathrm{C}$, namely $0.038 \%$ (MD) and $-0.005 \%$ (TD).

Table 5 presents the MD and TD accuracy of the previously R2R processed PET substrates after S2S processing.

The dimensions of R2R processed ST506 substrates changed $-0.435 \%$ in MD and $0.206 \%$ in TD after being S2S thermally treated for $30 \mathrm{~min}$ at $150{ }^{\circ} \mathrm{C}$ while unrestrained (Table 5). The MD shrinkage of $\mathrm{R} 2 \mathrm{R}$ processed substrate after the S2S cycle refers to the substrate's recovery towards its original dimensions. However, the main dimensional changes were observed after the first $\mathrm{S} 2 \mathrm{~S}$ cycle, and the changes of the second S2S cycle at $150{ }^{\circ} \mathrm{C}$ were only $-0.026 \%$ in MD and $-0.020 \%$ in TD. The dimensional changes of the previously $\mathrm{R} 2 \mathrm{R}$ processed PET substrate were more dependent on temperature while unstrained.

The MD accuracy of the substrate in the $R 2 R$ process after the first R2R cycle, and the recovery towards initial dimensions of unrestrained substrate after the S2S cycle can be explained by the polymer's intrinsic behaviour. If an unrestrained PET film is heated to a specific temperature $(>\mathrm{Tg})$, then once it has cooled, it will have reduced unrestrained ambient lengths that are dependent upon the temperature that it had been raised to. Essentially, there is an equilibrium length (in each direction) that is a function of that specific temperature. The length change upon heating is a release of "locked-in" or "frozen-in" strain (stretch) [18]. A key factor is that if this same film is raised again to the
Table 2 Key information in S2S and R2R processing; substrate tension force $(\mathrm{F})$, processing temperature $(\mathrm{T})$ and processing time (t). Processing conditions were determined by the needs of the printed materials used in the individual processing steps

\begin{tabular}{lll}
\hline Experiment & Key processing parameters \\
\cline { 2 - 3 } & S2S (A5 sheet) & R2R $(300 \mathrm{~mm}$ wide web) \\
\hline Stability of substrate & unstrained & $\mathrm{F}=80 \mathrm{~N}$ \\
PET (S2S, R2R), ITO-PET (R2R) & $\mathrm{T}=150,140,85^{\circ} \mathrm{C}$ & $\mathrm{T}=140{ }^{\circ} \mathrm{C}$ \\
& $\mathrm{t}=30 \mathrm{~min}$ & $\mathrm{t}=7 \mathrm{~min}$ \\
Accuracy of registration & unstrained & $\mathrm{F}=80 \mathrm{~N}$ \\
and printing (PET) & $\mathrm{T}=130{ }^{\circ} \mathrm{C}$ & $\mathrm{T}=100{ }^{\circ} \mathrm{C}$ \\
& $\mathrm{t}=30 \mathrm{~min}$ & $\mathrm{t}=1.4-7 \mathrm{~min}$ \\
OPV printing (ITO-PET) & - & $\mathrm{F}=80 \mathrm{~N}$ \\
& & $\mathrm{~T}=120-140^{\circ} \mathrm{C}$ \\
& & $\mathrm{t}=1.75-7 \mathrm{~min}$ \\
\hline
\end{tabular}


Table 3 Machine direction (MD) accuracy of Series I and Series II R2R processed HS-PET substrates after being thermally treated in the first $\mathrm{R} 2 \mathrm{R}$ cycle and second $\mathrm{R} 2 \mathrm{R}$ cycle

\begin{tabular}{lllllllc}
\hline Substrate & $\mathrm{T}\left[{ }^{\circ} \mathrm{C}\right]$ & $\begin{array}{l}\text { No. of } \\
\text { R2R cycles }\end{array}$ & Direction & $\begin{array}{l}\text { DEV } \\
{[\%]}\end{array}$ & $\begin{array}{l}\text { STD } \\
{[\%]}\end{array}$ & MAX-DEV [\%] & MIN-DEV [\%] \\
\hline R2R-ST506 (I) & 140 & 1 & MD & $\mathbf{0 . 3 1 3}$ & 0.008 & 0.332 & 0.298 \\
R2R-ST506 (I) & 140 & 2 & MD & $\mathbf{0 . 0 1 0}$ & 0.011 & 0.044 & -0.005 \\
R2R-PCS (I) & 140 & 1 & MD & $\mathbf{0 . 4 0 9}$ & 0.011 & 0.434 & 0.385 \\
R2R-PCS (I) & 140 & 2 & MD & $\mathbf{0 . 0 0 6}$ & 0.006 & 0.020 & 0.000 \\
R2R-ST504 (I) & 140 & 1 & MD & $\mathbf{0 . 3 6 0}$ & 0.019 & 0.395 & 0.319 \\
R2R-ST504 (I) & 140 & 2 & MD & $\mathbf{0 . 0 1 6}$ & 0.013 & 0.037 & 0.000 \\
R2R-ITO-ST504 (I) & 140 & 1 & MD & $\mathbf{0 . 2 0 6}$ & 0.032 & 0.261 & 0.129 \\
R2R-ITO-ST504 (I) & 140 & 2 & MD & $\mathbf{0 . 0 4 2}$ & 0.014 & 0.083 & 0.015 \\
R2R-ST506 (II) & 140 & 1 & MD & $\mathbf{0 . 3 5 7}$ & 0.009 & 0.376 & 0.341 \\
R2R-ST506 (II) & 140 & 2 & MD & $\mathbf{0 . 0 0 2}$ & 0.004 & 0.015 & 0.000 \\
R2R-PCS (II) & 140 & 1 & MD & $\mathbf{0 . 3 9 0}$ & 0.035 & 0.485 & 0.314 \\
R2R-PCS (II) & 140 & 2 & MD & $\mathbf{0 . 0 1 8}$ & 0.006 & 0.032 & 0.007 \\
\hline
\end{tabular}

same elevated temperature, then after re-cooling and release of tension, no further (or only minor) dimensional changes will take place, as the film was already at the equilibrium dimensions (length) for that elevated temperature. However, when using the PET film to fabricate printed electronics, manufacturers often need to apply heat while under tension (e.g. when coating and printing). During such processes, a small degree of stretch of the PET film will occur in the machine which is essentially the opposite of shrinkage. If the film is then cooled down while still under this tension, some of this additional stretch will be locked into the structure of the film, such that the subsequent film will have slightly longer dimensions in the direction of this stretch. In other words, some of the stretch has been "locked into" or "frozen into" the structure of the film. In this way, even a film that has been previously stabilized would now, upon re-heating, be subject once more to the length reduction (shrinkage) that a standard, non-stabilized film would exhibit.

Essentially, if a film is heated to a given temperature, and at a specified tension (in each direction), there will be corresponding equilibrium ambient dimensions that the film will settle to, once re-cooled. The process that occurs when a film is heated under nonzero tension is a change in the strain that is locked-in but under tension, it can be either be a decrease (i.e. length reduction or shrinkage) or an increase (i.e. length increase or stretch) in the locked-in strain. The change will depend upon the relative size of the shrinkage force at the elevated temperature vs the tension used [29]. For that reason, the dimensional change upon reheating under no tension is expected to show an increased shrinkage equivalent to the increase in frozen-in strain due to the pre-processing treatment. Figure 3 graphically depicts the dimensional stability of ST506 substrate after S2S temperature treatment.

In S2S processing, the preliminary thermal treatment prior to S2S printing improves significantly the dimensional accuracy of the ST506 substrate. It also should be noted that the combination of R2R and S2S printing would decrease the dimensional accuracy due to the different thermal annealing conditions and applied tensions.
Table 4 Machine direction (MD) and transverse direction (TD) accuracy of untreated HS-PET substrate ST506 after first and second S2S cycle

\begin{tabular}{lllrlll}
\hline $\mathrm{T}\left[{ }^{\circ} \mathrm{C}\right]$ & $\begin{array}{l}\text { No. of } \\
\text { S2S cycles }\end{array}$ & Direction & DEV [\%] & STD [\%] & MAX-DEV [\%] & MIN-DEV [\%] \\
\hline 150 & 1 & MD & $\mathbf{- 0 . 0 9 7}$ & 0.072 & 0.058 & -0.304 \\
150 & 1 & TD & $\mathbf{- 0 . 1 3 4}$ & 0.138 & 0.109 & -0.513 \\
150 & 2 & MD & $\mathbf{0 . 0 2 4}$ & 0.138 & 0.441 & -0.445 \\
150 & 2 & TD & $\mathbf{- 0 . 0 1 3}$ & 0.104 & 0.383 & -0.197 \\
140 & 1 & MD & $\mathbf{- 0 . 0 3 8}$ & 0.116 & 0.241 & -0.436 \\
140 & 1 & TD & $\mathbf{- 0 . 0 0 6}$ & 0.155 & 0.470 & -0.519 \\
85 & 1 & MD & $\mathbf{0 . 0 3 8}$ & 0.085 & 0.185 & -0.246 \\
85 & 1 & TD & $\mathbf{- 0 . 0 0 5}$ & 0.055 & 0.182 & -0.204 \\
\hline
\end{tabular}




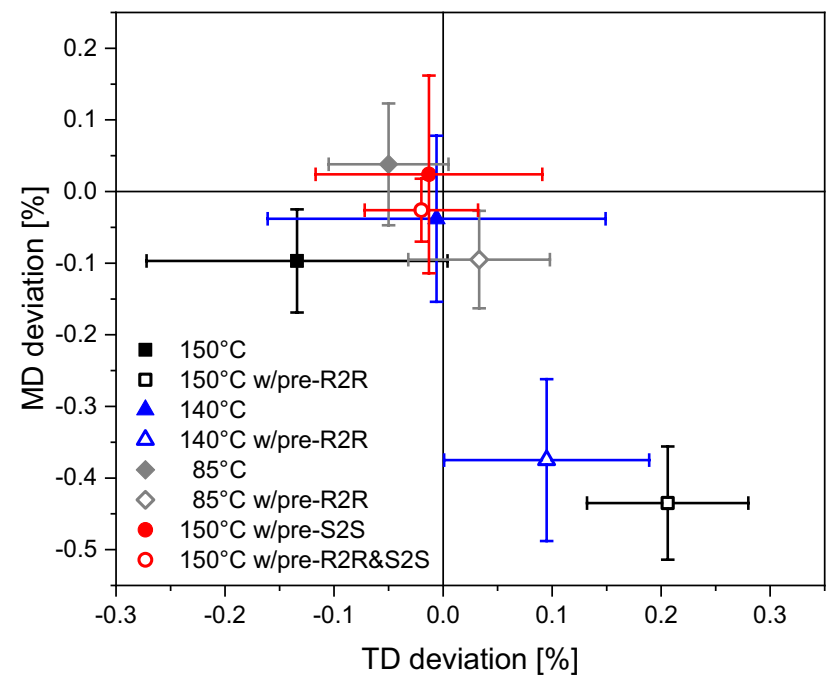

Fig. 3 Machine direction (MD) and transfer direction (TD) accuracy of untreated and preliminary R2R-processed (at $140{ }^{\circ} \mathrm{C}$ ) and S2Sprocessed (at $150{ }^{\circ} \mathrm{C}$ ) HS-PET ST506 substrate after being thermally treated in $\mathrm{S} 2 \mathrm{~S}$ cycle

\subsection{Impact of pre-processing on PET film properties}

It has been evaluated that the pre-processing of the PET films does not significantly impact the film quality at these experimental temperatures. Furthermore, the flexibility of the BOPET film is a function of thickness and tensile strength properties which are not altered by the pre-heat treatments $[23,24]$. For example, the mechanical and optical properties due to molecular orientation, chain length and level of crystallinity will not change significantly. A differential scanning calorimetry (DSC) assessment was performed on the substrates before and after treatment, which showed no significant differences in the low temperature peak, LTP peak (related to the temperature the film at which the film was crystallized after orientation) or the $\mathrm{T}_{\mathrm{mp}}$ (melting temperature of the film changing from solid to liquid phase) (Table 6). DSC graphs are presented in Supplementary Information $\mathrm{S} 2$.
Even though no significant change in the PET morphology can be detected with the DSC assessment, a slight but statistically significant increase in haze and a change in transmittance can be observed as result of subsequent treatments (see Fig. 4 with one-way ANOVA charts below). This can be explained and is entirely consistent with an oligomer migration phenomenon (also called "blooming"). It is a physical process which happens as result of exposure of film to higher temperature for an extended time. The higher the temperature and the longer the exposure is, the worse the blooming and causes the film to have a milky appearance, yet it is possible to remove by washing the PET surface with methylethylketone solvent [18]. Changes are very small and when limited to a single extra processing step, unlikely to be noticed.

\subsection{Alignment of printed multilayered architectures}

As mentioned in the Introduction, the registration accuracy of the printed layers is critical in printed electronics devices since the layer-to-layer alignment between the printed layers directly affects the electronic device performance. For example, misaligned multilayer films can negatively impact electronic device performance by decreasing the active area, causing open or incomplete circuits or creating short circuits. Examples of multilayer registration in printed electronics applications is shown in Fig. 5.

In $\mathrm{R} 2 \mathrm{R}$ printing, automatic camera-based registration systems are typically used. These systems require camerareadable registration marks printed by every printing unit at predetermined distances from each other. Reference registration marks are printed with the first layer and all the following layers are registered to these reference marks. The registration system used in this work holds $\pm 5 \mu \mathrm{m}$ sensor accuracy and suits for processing of opaque, transparent, reflecting substrates and materials such as paper, film and metallized substrates. The registration camera is located directly after the printing unit and takes photos of the printed marks to control for accuracy. The registration system constantly measures the distance between the reference and
Table 5 Machine direction (MD) and transverse direction (TD) accuracy of previously R2R processed HS-PET substrate ST506 after first and second S2S cycle

\begin{tabular}{llllrlll}
\hline $\mathrm{T}\left[{ }^{\circ} \mathrm{C}\right]$ & $\begin{array}{l}\text { No. of } \\
\text { R2R cycles }\end{array}$ & $\begin{array}{l}\text { No. of } \\
\text { S2S cycles }\end{array}$ & Direction & DEV [\%] & STD [\%] & MAX-DEV [\%] & MIN-DEV [\%] \\
\hline 150 & 1 & 1 & MD & $\mathbf{- 0 . 4 3 5}$ & 0.079 & -0.175 & -0.680 \\
150 & 1 & 1 & TD & $\mathbf{0 . 2 0 6}$ & 0.074 & 0.357 & -0.012 \\
150 & 1 & 2 & MD & $\mathbf{- 0 . 0 2 6}$ & 0.044 & 0.113 & -0.146 \\
150 & 1 & 2 & TD & $\mathbf{- 0 . 0 2 0}$ & 0.052 & 0.117 & -0.140 \\
140 & 1 & 1 & MD & $\mathbf{- 0 . 3 7 5}$ & 0.113 & 0.008 & -0.710 \\
140 & 1 & 1 & TD & $\mathbf{0 . 0 9 5}$ & 0.094 & 0.277 & -0.075 \\
85 & 1 & 1 & MD & $\mathbf{- 0 . 0 9 5}$ & 0.068 & 0.078 & -0.256 \\
85 & 1 & 1 & TD & $\mathbf{0 . 0 3 3}$ & 0.065 & 0.256 & -0.175 \\
\hline
\end{tabular}



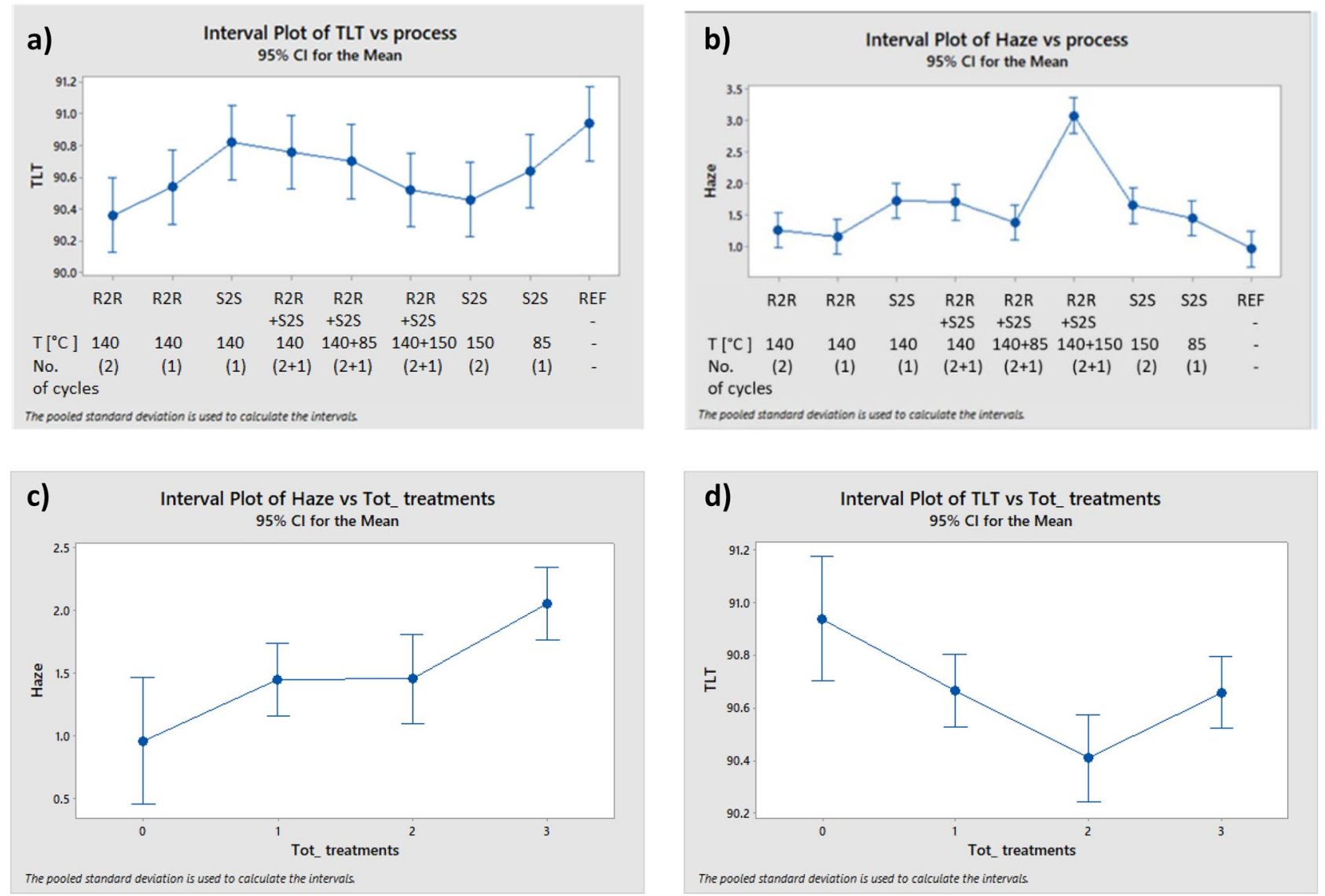

Fig. 4 a-b) Haze and total light transmittance of the PET, and c-d) Haze and total light transmittance of the PET samples as function of total number of R2R and S2S processing cycles

actively printed registration marks and adjusts the layerto-layer alignment. For the MD registration, the rotational speed of the printing rollers in the printing unit is varied, whereas for the TD registration, the physical location of the printing unit perpendicular to the substrate is controlled. The measured registration has either positive or negative values depending on its location relative to its optimal position. In MD, a negative value states that the overprinted layer is behind its optimum position, and a positive value implies that the overprinted layer is ahead of its optimum position.
In TD, the overprinted layer can be offset either left $(+)$ or right (-) from its correct position.

The registration accuracy of the utilized R2R printing system plays a major role in the final alignment quality of the printed electronics devices. The registration accuracy in both machine (MD) and transverse (TD) directions in a single R2R rotary screen printing run (with the cylinder circumference of $409.570 \mathrm{~mm}$ and $300-\mathrm{mm}$ web width) using an automatic registration system is shown in Fig. 6. The registration fluctuates around the optimal registration value of

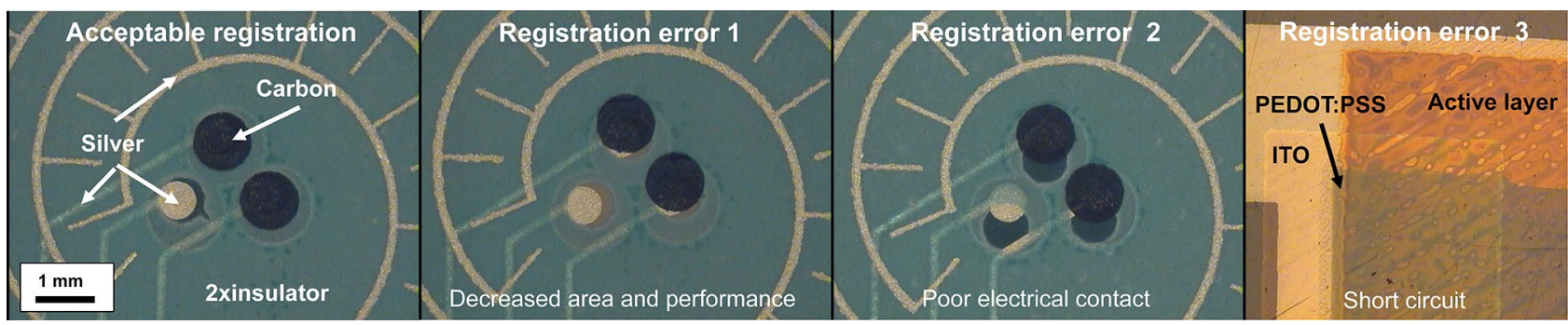

Fig. 5 Effect of the layer-to-layer registration on the layer quality and printed electronics device performance 


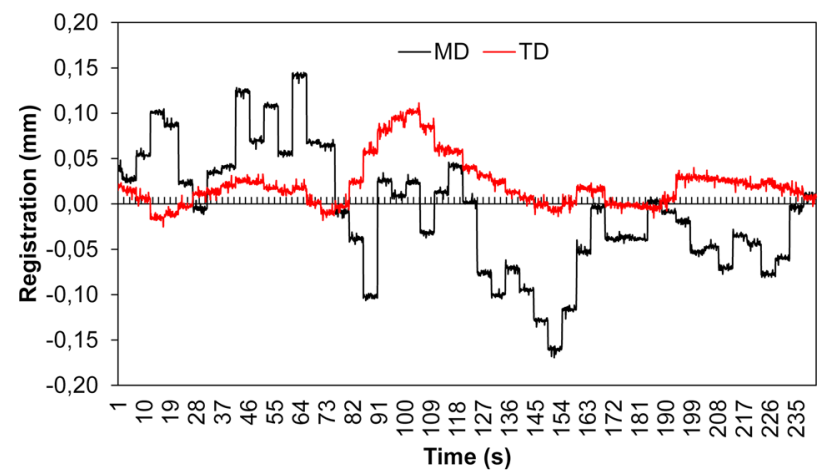

Fig. 6 Variation of the registration in a single R2R rotary screen print run in both machine (MD) and transverse (TD) directions

$0 \mu \mathrm{m}$ in both directions but the fluctuations are larger in MD than in TD. In MD, the registration varies between $-169 \mu \mathrm{m}$ and $+145 \mu \mathrm{m}$ resulting from the fluctuations in the substrate dimensions and web tension, changes in the rotational speed of the printing rollers, as well as oscillations created by the mechanical bearings, shafts and gears of the printing press. In TD, the registration varies between $-25 \mu \mathrm{m}$ and $+111 \mu \mathrm{m}$. The registration accuracy in TD is mostly affected by the dimensional changes of the substrate since the adjustment of the position of the printing unit does not affect the web tension of the process much.

Table 7 presents the registration accuracy of the different $\mathrm{R} 2 \mathrm{R}$ printing processes when the printing is done on untreated HS-PET Melinex ST506 substrate. The registration data of each printing method is calculated from two $\mathrm{R} 2 \mathrm{R}$ print runs having different printing speeds. The utilized printing speeds were $2 \mathrm{~m} / \mathrm{min}$ and $5 \mathrm{~m} / \mathrm{min}$ in rotary screen printing and $5 \mathrm{~m} / \mathrm{min}$ and $10 \mathrm{~m} / \mathrm{min}$ in gravure and flexographic printing. As expected, the accuracy (MAX, MIN) and fluctuation (STD) of the registration is significantly better in TD than in MD due to the smaller effect of the web tension in the transverse direction of the substrate. The average (AVG) registration of the different print runs is rather close to $0 \mu \mathrm{m}$ but some larger errors are seen with gravure printing in MD and with rotary screen printing in TD. However, the AVG value is significantly less than $50 \mu \mathrm{m}$, which

Table 6 Crystallization (LTP) and melting $\left(\mathrm{T}_{\mathrm{mp}}\right)$ peak temperatures of untreated and R2R and S2S processed substrates

\begin{tabular}{lll}
\hline Substrate & LTP $\left[{ }^{\circ} \mathrm{C}\right]$ & $\mathrm{T}_{\mathrm{mp}}\left[{ }^{\circ} \mathrm{C}\right]$ \\
\hline ST506 (no treatment) & 227.3 & 252.7 \\
R2R ST506-Rt (after R2R process) & 227.8 & 251.1 \\
R2R ST506-Rt-St (after R2R+S2S process) & 228.3 & 254.3 \\
\hline
\end{tabular}

is considered as good registration. The AVG registration should optimally be close to $0 \mu \mathrm{m}$ since the automatic registration system tends to keep the layer-to-layer alignment as accurate as possible throughout the runs despite the process fluctuations.

The printing method has some effect on the registration accuracy, i.e. the largest absolute MAX or MIN value. In MD, the registration accuracy of rotary screen printing, gravure, and flexography is $169 \mu \mathrm{m}, 146 \mu \mathrm{m}$, and $191 \mu \mathrm{m}$, respectively. In TD, the accuracy is $111 \mu \mathrm{m}$ in rotary screen printing, $127 \mu \mathrm{m}$ in gravure and $76 \mu \mathrm{m}$ in flexography. Gravure printing gives the most accurate registration in MD, i.e. the lowest MAX-MIN value, but the poorest accuracy in TD. By contrast, the poorest accuracy in MD is exhibited with flexography printing. In gravure printing, the hard printing cylinder and higher nip pressure prevent the substrate slipping in the printing direction, thus providing good alignment accuracy in MD. However, the transverse-directional registration is poorer since the high nip pressure can delay or prevent the registration adjustment. On the other hand, flexography and rotary screen printing use flexible printing plates and screens with low nip pressure, thus giving better register adjustment in TD but higher substrate slip to MD.

The registration accuracy depends on the printing speed, as shown in Fig. 7. As the printing speed increases with all the tested R2R printing methods, the registration becomes less accurate, i.e. higher MAX-MIN value, in both TD and MD. This comes from the fact that the web tension fluctuates, and therefore the need for the adjustments, increase at higher printing speeds. In addition, the registration system must simultaneously tackle the adjustments faster, thus increasing the MAX-MIN value. The smallest changes of less than $20 \mu \mathrm{m}$ are seen with rotary screen printing. However, the changes in the registration accuracy are less than 50 $\mu \mathrm{m}$ with the changing printing speed. Therefore, the effect of the printing speed on the registration accuracy is considered to be very small.

In this study, it has been shown that the preliminary R2R thermal treatment of the substrate will improve the registration accuracy through the improved substrate performance by decreasing the dimensional changes of the substrate during printing as the MD elongation reduced from $0.357 \%$ to $0.002 \%$ (PET) and from $0.206 \%$ to $0.042 \%$ (ITO-PET), thus improving the web tension controllability. However, the registration accuracy of the printing press should be taken into account when designing multilayer printed electronics devices to avoid the deterioration of the device performance. It is recommended that a tolerance is provided to account for misalignment of the printed layers in every direction within the limits of the utilized registration system without creating short circuits, decreasing active areas of the devices, or 
Fig. 7 Effect of the printing speed on the registration accuracy (MAX-MIN) of different R2R print runs in both TD (left) and MD (right)
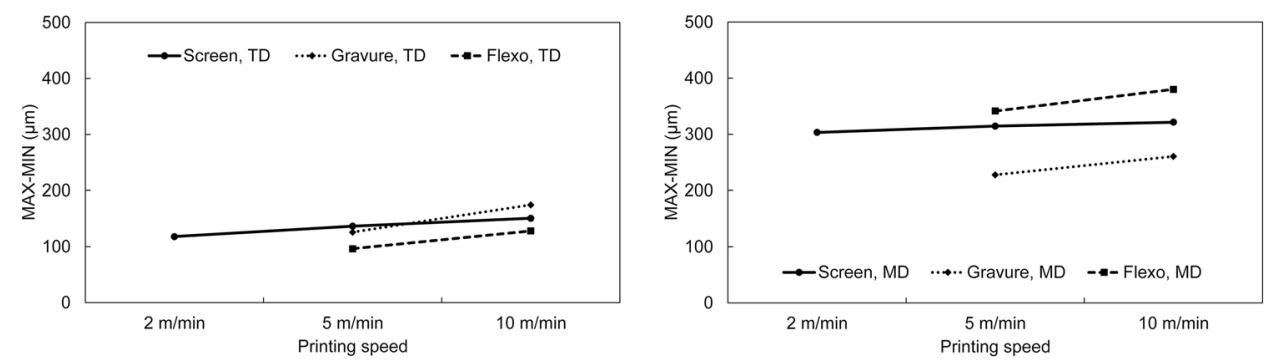

hindering the formation of electrical contacts. This means that the dimensions of the printed layers should be larger than in the optimum case where the perfect registration of $0 \mu \mathrm{m}$ is achieved. Thus, the MAX, MIN and MAX-MIN values of the registration of the printing system aid in the design of the multilayer electronic devices. For example, considering the utilized R2R printing press above, the layers should have tolerance to move at least $333 \mu \mathrm{m}( \pm 167 \mu \mathrm{m})$ with rotary screen printing, $260 \mu \mathrm{m}( \pm 130 \mu \mathrm{m})$ in gravure, and $381 \mu \mathrm{m}( \pm 191 \mu \mathrm{m})$ in flexography without creating performance issues. Please note that many printed electronics manufacturing processes combine several different printing and deposition techniques. Therefore, for a multilayered thin film stacked architecture, the deposition method with the poorest registration accuracy determines the design limits for the whole device.

The effect of the preliminary S2S thermal treatment of the HS-PET substrate on the registration accuracy of the S2S printed multilayer structures in MD is presented in Table 8 . The preliminary S2S thermal treatment of the substrate improves the average registration accuracy by $40 \%$ from $81 \mu \mathrm{m}$ to $48 \mu \mathrm{m}$. In addition, the maximum and minimum registration values are $33-43 \%$ smaller with the pre-treated substrate sheets than with the un-treated sheets. The S2S treatment above the glass transition temperature ( $\mathrm{Tg}$ ) of the substrate stabilizes the substrate dimensions by relaxing the polymer chains and residual strains within the plastic films. Therefore, any biaxial shrinkage or expansion of the plastic substrate sheet should take place during the preliminary S2S cycle, thus giving a dimensionally stabilized substrate for multilayer printing and thermal annealing. In R2R printing, the web tension plays a role in the substrate stabilization and in the following printing processes. It is, thus, expected that the registration accuracy is slightly poorer in continuous $R 2 R$ processes than in $S 2 S$ processes.

\subsection{Printed free-form electronic devices}

The multilayered OPV structure was chosen as a case study to evaluate the fabrication and performance of multilayer printed free-form optoelectronic devices. This is particularly important for electronic devices that pattern by printing (i.e. gravure, screen, flexographic) and all R2R deposited thin film layers providing incredible flexibility for design freedom. Nevertheless, there are a variety of methods to fabricate $2 \mathrm{D}$ designs for multilayered stacks, which includes R2R compatible processes such as slot-die coating and laser patterning [30].

The fabricated OPV structure comprised five R2R printed or R2R patterned layers with the configuration of PET/ITO/ $\mathrm{ZnO} / \mathrm{P} 3 \mathrm{HT}$ :PCBM/PEDOT:PSS/Ag. First, ITO was patterned as a negative image in rotary screen printing process via wet etching. Next, $\mathrm{ZnO}$ was gravure printed as an electron transport layer and P3HT:PCBM as a photoactive layer. PEDOT:PSS was rotary screen-printed as a hole transport layer and silver as the hole contact. Figure 8 presents the processing equipment and the process flow that were used in the fabrication of all OPV designs presented in this paper.

The solar cells were designed with an overlap between the printed layers to obtain the serial connection between the cells through the ITO and silver layers. Triangle design comprised three modules with seven serially connected cells where the modules were connected with each other in
Table 7 Registration accuracy of different R2R printing processes using untreated HS-PET (ST506) substrate

\begin{tabular}{lllllll}
\hline Printing method & Direction & AVG $[\mu \mathrm{m}]$ & STD $[\mu \mathrm{m}]$ & MAX $[\mu \mathrm{m}]$ & MIN $[\mu \mathrm{m}]$ & MAX-MIN $[\boldsymbol{\mu m}]$ \\
\hline Rotary screen & MD & -4 & 64 & 164 & -169 & $\mathbf{3 3 3}$ \\
& TD & 31 & 26 & 111 & -25 & $\mathbf{1 3 7}$ \\
Gravure & MD & 38 & 60 & 146 & -114 & $\mathbf{2 6 0}$ \\
\multirow{5}{*}{ Flexography } & TD & 5 & 29 & 127 & -93 & $\mathbf{2 2 0}$ \\
& MD & -6 & 86 & 190 & -191 & $\mathbf{3 8 1}$ \\
& TD & 8 & 20 & 76 & -68 & $\mathbf{1 4 4}$ \\
\hline
\end{tabular}


Fig. 8 R2R fabrication of OPV with MAXI pilot-line printing machine using rotary screen printing (RS) for the patterning of ITO electron contact, gravure printing $(\mathrm{G})$ for electron transporting (ETL) and photoactive layer and RS for hole transport layer (HTL) and hole contact layer

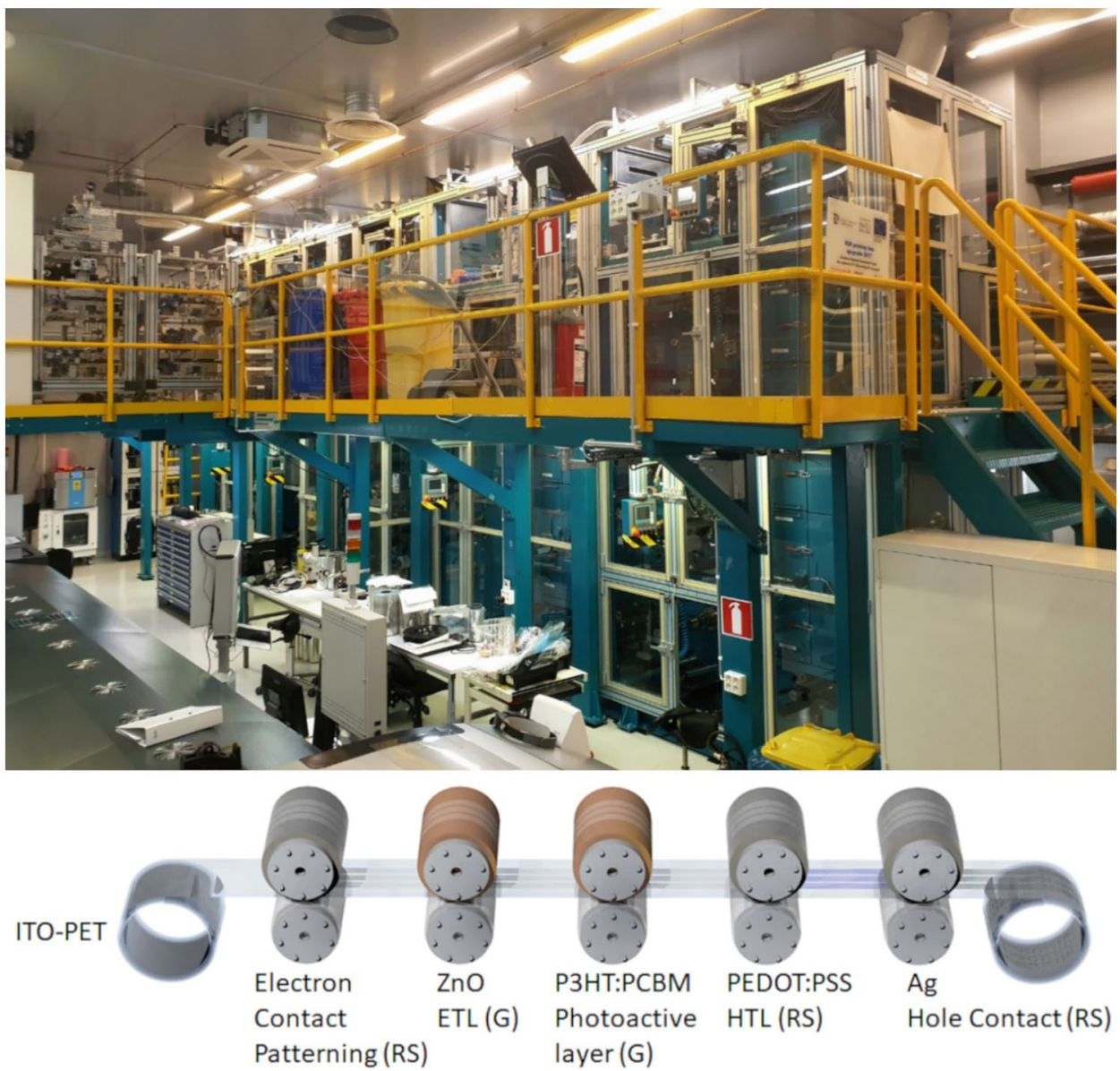

parallel (Fig. 9a). Santa Claus and Camouflage designs comprised a module with eight cells in series (Fig. 9b). Calligraphy design comprised seven modules where each module comprised ten cells in series. The seven modules were connected with each other in parallel to form Fig. 9c Calligraphy layout. For the continuous large-area calligraphy pattern, the repetition lengths were connected with each other in parallel.

As already mentioned, for designing R2R printed electronics, the registration accuracy needs to be considered during the layout design by controlling the size of the printed forms. In practice, this means that the layers require some increase to their optimal dimensions to meet the limitations of the printing accuracy. With this is mind, the layers endure their desired overlap to avoid a decrease in performance or short circuits, even though the layer-to-layer registration may fluctuate during the R2R print run. Accordingly, the dimensions of the layers should be tuned according to the registration performance of the utilized printing press and registration system. Table 9 presents minimum layer-to-layer offset for each printed layer for free-form designs.
Each layer was designed to have an offset to the previous layer and a tolerance to cover the influences caused by printing inaccuracy and layer-to-layer misalignment. Based on earlier study of Välimäki et al. gravure printed P3HT:PCBM and screen-printed silver are relatively close to the nominal values of the layout, whereas gravure printed $\mathrm{ZnO}$ ink is prone to spreading, and screen-printed PEDOT:PSS paste prone to shrinking [2]. Here, the designed Santa Claus and Camouflage shapes comprise small features with the higher complexity of form factor thus, being more sensitive to critical misalignment, whereas Triangle design comprise the larger tolerances due to the significantly large size of a single cell. The tolerances of the calligraphy design are very close to or even below the limits of the registration system of the utilized R2R printing line, as stated in Section 3.4. Four OPV designs with varying degrees of complexity were prepared with the MAXI pilot printing line (Fig. 10).

Current-voltage characteristics show that the printed Santa Claus, Camouflage and Triangle modules reached the same or even higher average open-circuit voltage $\left(V_{o c}\right)$ than 
a.)

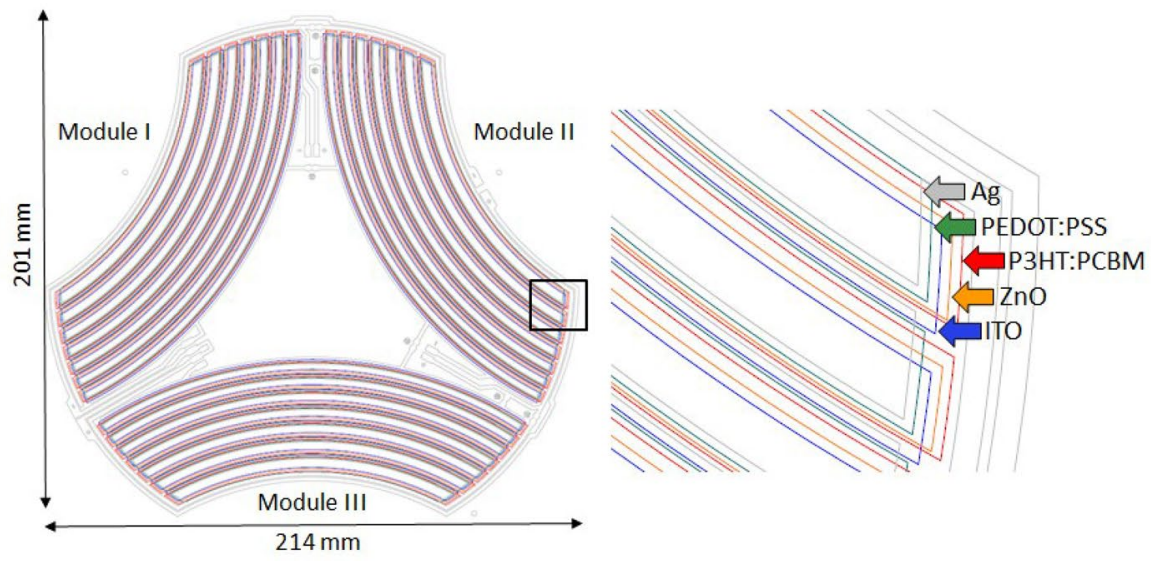

b.)
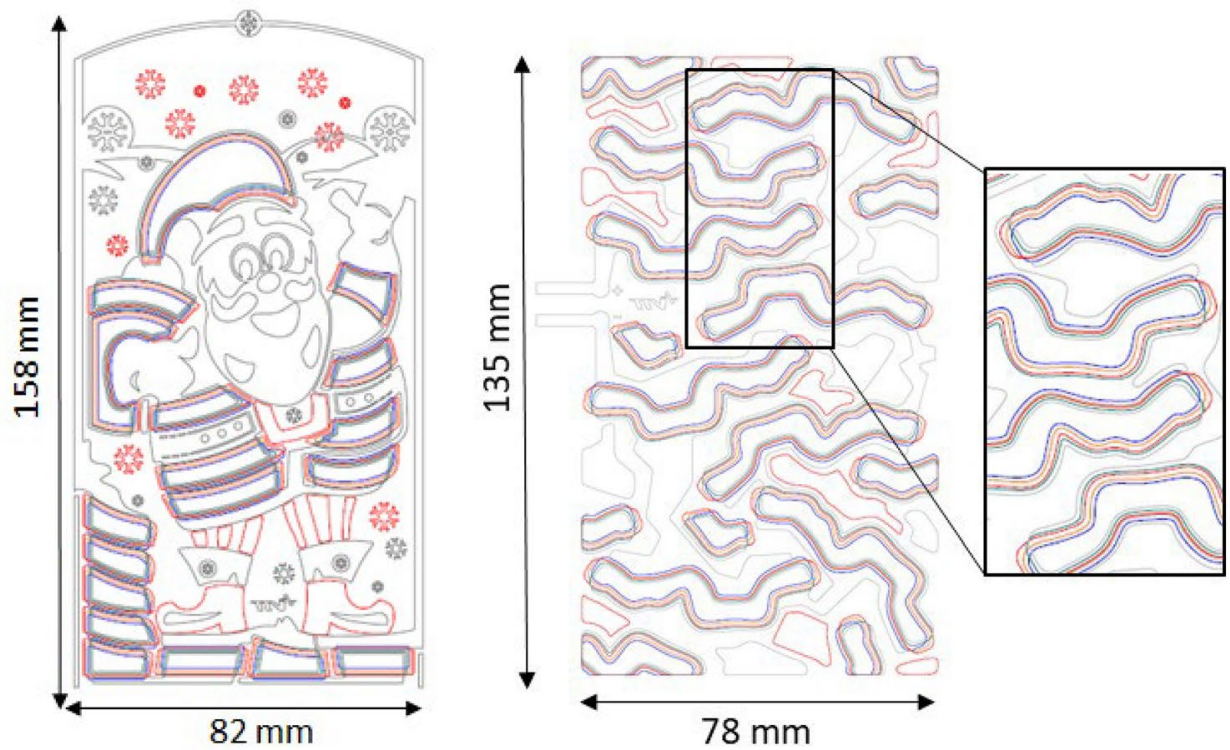

c.)
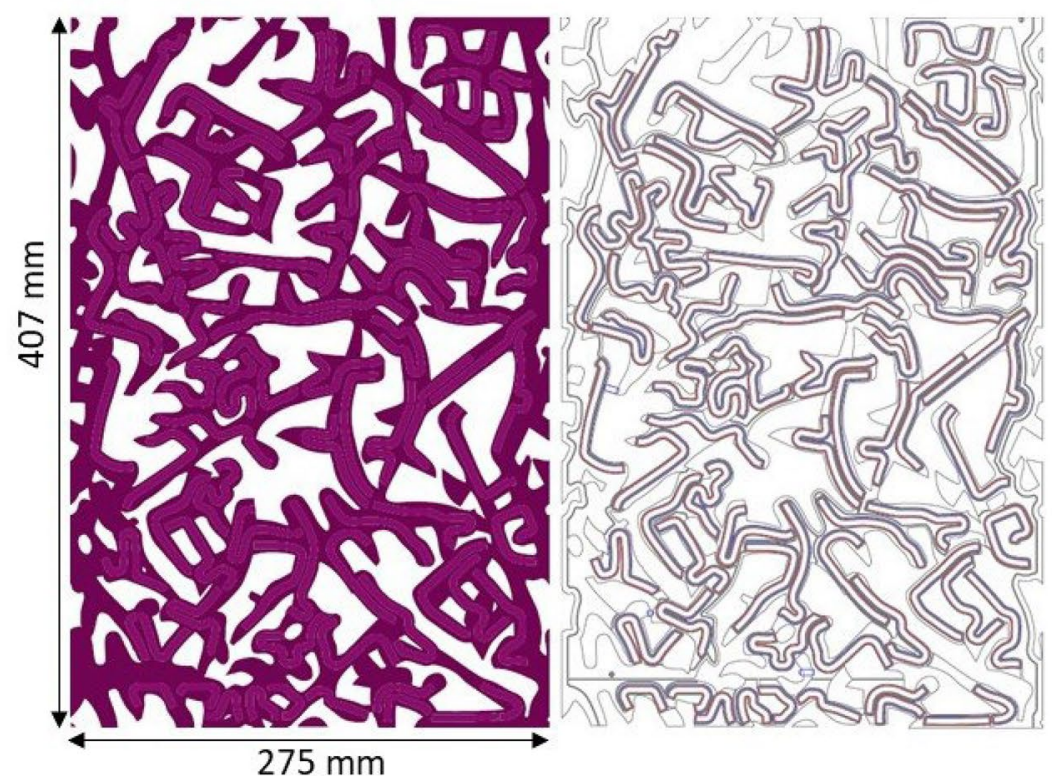

Fig. 9 Layouts for R2R printing of OPV with a) Triangle, b) Santa Claus and Camouflage and c) Calligraphy (layout on left with and on right without additional graphics) designs 
Table 8 Effect of the thermal pre-treatment of the HS-PET substrate (ST506) on the registration accuracy in $\mathrm{MD}$ in S2S printing

\begin{tabular}{llllll}
\hline & AVG $[\mu \mathrm{m}]$ & STD $[\mu \mathrm{m}]$ & MAX $[\mu \mathrm{m}]$ & MIN $[\mu \mathrm{m}]$ & MAX-MIN $[\mu \mathrm{m}]$ \\
\hline No pre-treatment & 81 & 12 & 101 & 41 & 60 \\
Thermal pre-treatment & 48 & 11 & 67 & 23 & 44 \\
Difference & 33 & 1 & 34 & 18 & 16 \\
\hline
\end{tabular}

the standard Rectangle-shaped module (Table 10). In comparison with the Rectangle-shaped module, the short-circuit current $\left(\mathrm{I}_{\mathrm{sc}}\right)$ and fill factor (FF) of the Camouflage-shaped module was similar and with the Santa Claus-shaped module slightly lower. The changes in the active area of the solar cell caused by layer-to-layer inaccuracy result fluctuation in $\mathrm{I}_{\mathrm{sc}}$; however, the printed free-form shapes obtained functionality that was comparable with the reference Rectangle-shaped OPV.

The performance of the free-form OPV is comparable to the performance of rectangle OPV. However, if the module size increases to a full repetition length of $407 \mathrm{~mm}$ (in the $\mathrm{MD})$, as with the calligraphy design, the device performance is more challenging to maintain with $300-400 \mu \mathrm{m}$ registration tolerance due to the fluctuation of registration. The effect of the registration accuracy on the performance of the printed multilayer OPV modules with ten cells in series using the Calligraphy design is shown in Fig. 11. The registration accuracy of these multilayer devices is calculated as a sum of registration errors of each printed layer and the cells are arranged in the order of the alignment accuracy. In total, four layers were deposited onto the patterned ITO-PET and the registration is measured in both MD and TD. As the registration accuracy improves, $\mathrm{V}_{\mathrm{oc}}$ increases. This results from the fact that the good electrical contacts to the device are formed, and no short circuits are seen as the printed layers are properly aligned with each other. However, the performance remains rather constant after a certain threshold registration accuracy is reached. It is also seen that the registration in TD is much better and more even than in MD. When the registration sum is more than $2000 \mu \mathrm{m}$ (cell numbers 170 , 171, 172 and 158), the $\mathrm{V}_{\text {oc }}$ values are less than $3 \mathrm{~V}$. As the sum of registration accuracies decreases below $600 \mu \mathrm{m}$ (cell numbers 210 and 209), the $V_{o c}$ increases above 5 V. Figure 11 also shows the $\mathrm{V}_{\mathrm{oc}}$ of the OPV as a function of average registration and average maximum registration error. There is a strong correlation between the layer-to-layer registration and the device performance. The poorer the registration, the lower the open-circuit voltage, thus the poorer the device performance. When the average registration is less than 150 $\mu \mathrm{m}$ and the maximum average registration error is less than $230 \mu \mathrm{m}, \mathrm{V}_{\mathrm{oc}}$ of OPV Calligraphy design with ten serially connected cells is 4.7-5.2 V. The poorest $\mathrm{V}_{\text {oc }}$ of less than $0.5 \mathrm{~V}$ is seen when the average and maximum average registration errors are more than $300 \mu \mathrm{m}$ and $700 \mu \mathrm{m}$, respectively. It is, thus, evident that when the maximum registration error is less than $300 \mu \mathrm{m}$ and the MAX-MIN error of the printing system has been taken into account in the OPV device design, the performance of the device can be optimized.

Calligraphy OPV modules were used to build a decorative large-area smart glass façade element, shown in Fig. 12. In the demonstrator, Calligraphy OPV modules were combined with both a flexographic printed graphic foil and a LED foil with screen-printed silver wirings. The whole stack was then
Fig. $10 \mathrm{R} 2 \mathrm{R}$ printed freeform $\mathbf{a})$ OPV films and b) OPV module a.)

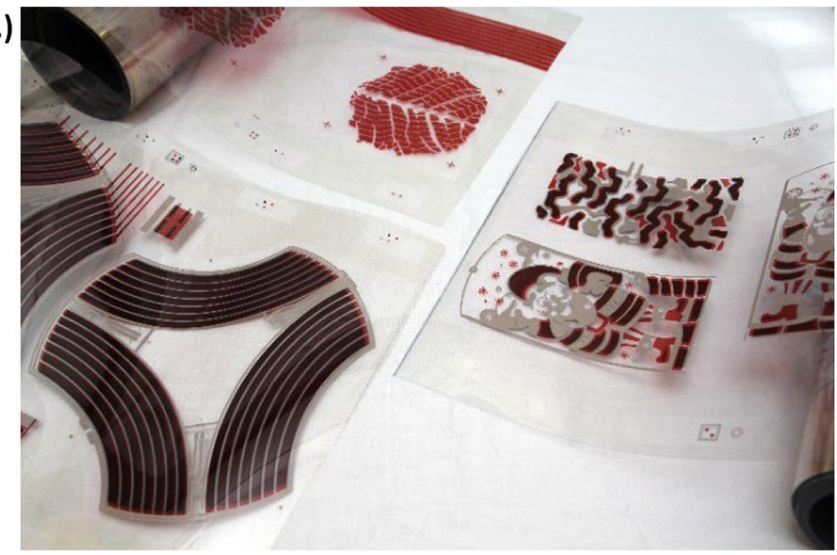

b.)

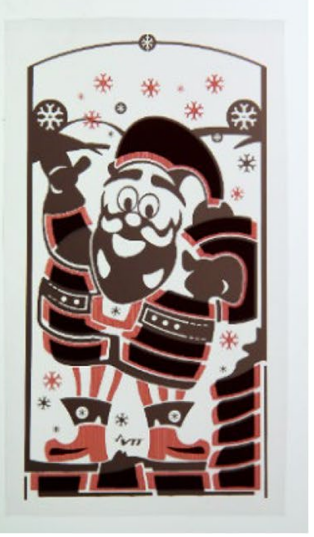


Table 9 Minimum layer-to-layer offset in the layout of R2R printed free-form OPV designs

\begin{tabular}{llll}
\hline Design & $\begin{array}{l}\text { Santa Claus } \\
\& \\
\text { Camouflage }\end{array}$ & Triangle & Calligraphy \\
& MIN $[\mu \mathrm{m}]$ & MIN $[\mu \mathrm{m}]$ & MIN $[\mu \mathrm{m}]$ \\
\hline Material & $<600$ & $<600$ & $<400$ \\
ITO-ZnO & $<600$ & $<800$ & $<400$ \\
ITO-P3HT:PCBM & $<600$ & $<400$ & $<400$ \\
P3HT:PCBM-PEDOT:PSS & $<400$ & $<500$ & $<400$ \\
PEDOT:PSS-Ag & $<400$ & $<500$ & $<300$ \\
Ag-ITO & & &
\end{tabular}

laminated together between glass panels. It is shown that the fabrication of these kinds of decorative large-area devices requires not only a good layer-to-layer registration in the multilayer printing processes within a single foil but also good alignment accuracies when combining all the separately patterned foils together. Therefore, the thermal pretreatment of the foils is important before any processing to stabilize the substrate dimensions [31].

\subsection{Design rules for $\mathrm{R} 2 \mathrm{R}$ processing of printed free form electronics}

The design of free-form electronics should take into account the limitations of the printing process and printing methods, as well as the printing ink and substrate materials. The minimum achievable line width depends on the printing method and on the ink properties. For example, the minimum achievable line width in rotary screen printing is approximately $100 \mu \mathrm{m}$, but in flexography, 20-40- $\mu \mathrm{m}$ wide lines can be easily reproduced. In addition, reduced ink viscosity typically increases the ink spreading on the substrate, thus increasing the achievable line width [32]. However, other ink properties, such as surface tension and rheology, also affect the ink transfer, substrate wetting, layer levelling on the substrate, and ink layer spreading. The surface energy and roughness of the substrate can also change the ink transfer and ink behaviour on the surface of the substrate. For example, ink can flow into the irregularities of the substrate surface, thus changing the dimensions of the patterns and creating irregularities in the film topology.

The registration accuracy of the printing system should also be taken into account in multilayer printings, as mentioned earlier. Each printed layer should provide tolerance in the layouts to allow for some misalignment without having an effect on the device performance. This requires that the deposited layers are designed for sufficient overlap which implies that one must have the knowledge of the limitations of the registration system in use. For example, with MAXI $\mathrm{R} 2 \mathrm{R}$ printing machine with the automated registration system that was used, each deposited layer should be able to misalign by $300-400 \mu \mathrm{m}$ without affecting the device performance. This applies for all the printing methods available in the MAXI line and for multilayer structures having more than two layers. To verify this, a demonstration was prepared by printing OPV devices into a form of a Santa Claus, Camouflage, Triangle and Calligraphy.

If a series of patterns of specific dimensions is printed onto a PET sheet, then only very small dimensional changes between processing stations can be tolerated, or there will be registration issues with subsequent printed patterns. The length of the film under tension at ambient temperature before and after each stage will change significantly only through the first processing station $(0.357 \%$ in MD), and not subsequent ones ( $0.002 \%$ in MD). For that reason, substrate pre-treatment prior printing is recommended as demonstrated in the findings of this study.
Table 10 Electrical parameters of R2R fabricated OPV structures printed with the following designs: Rectangle, Santa Claus, Camouflage and Triangle. OPVs measured under AM 1.5 solar simulator under illumination of $100 \mathrm{~mW} / \mathrm{cm}^{2}$

\begin{tabular}{lllllrlll}
\hline Design & $\begin{array}{l}\text { Active cell } \\
\text { area }\left[\mathrm{cm}^{2}\right]\end{array}$ & $\begin{array}{l}\mathrm{V}_{\text {oc }}[\mathrm{V}] \\
\text { (per cell) }\end{array}$ & $\mathrm{V}_{\mathrm{mpp}}[\mathrm{V}]$ & $\mathrm{I}_{\mathrm{sc}}[\mathrm{mA}]$ & $\mathrm{I}_{\mathrm{mpp}}[\mathrm{mA}]$ & $\mathrm{FF}$ & PCE [\%] & $\mathrm{P}_{\mathrm{mpp}}[\mathrm{mW}]$ \\
\hline Rectangle & 13.60 & $4.52(0.56)$ & 3.10 & 15.45 & 10.74 & 0.48 & 2.45 & 33.28 \\
Santa Claus & 13.08 & $4.48(0.56)$ & 2.90 & 12.49 & 8.86 & 0.46 & 1.97 & 25.70 \\
Camouflage & 15.56 & $4.64(0.58)$ & 3.15 & 18.01 & 12.61 & 0.48 & 2.55 & 39.72 \\
Triangle (left) & 26.94 & $3.66(0.52)$ & 2.40 & 31.82 & 21.68 & 0.45 & 1.93 & 52.03 \\
Triangle (right) & 26.94 & $3.90(0.56)$ & 2.60 & 35.91 & 25.61 & 0.48 & 2.47 & 66.59 \\
Triangle (bottom) & 26.94 & $3.90(0.56)$ & 2.45 & 36.09 & 25.46 & 0.44 & 2.32 & 62.37 \\
\hline
\end{tabular}



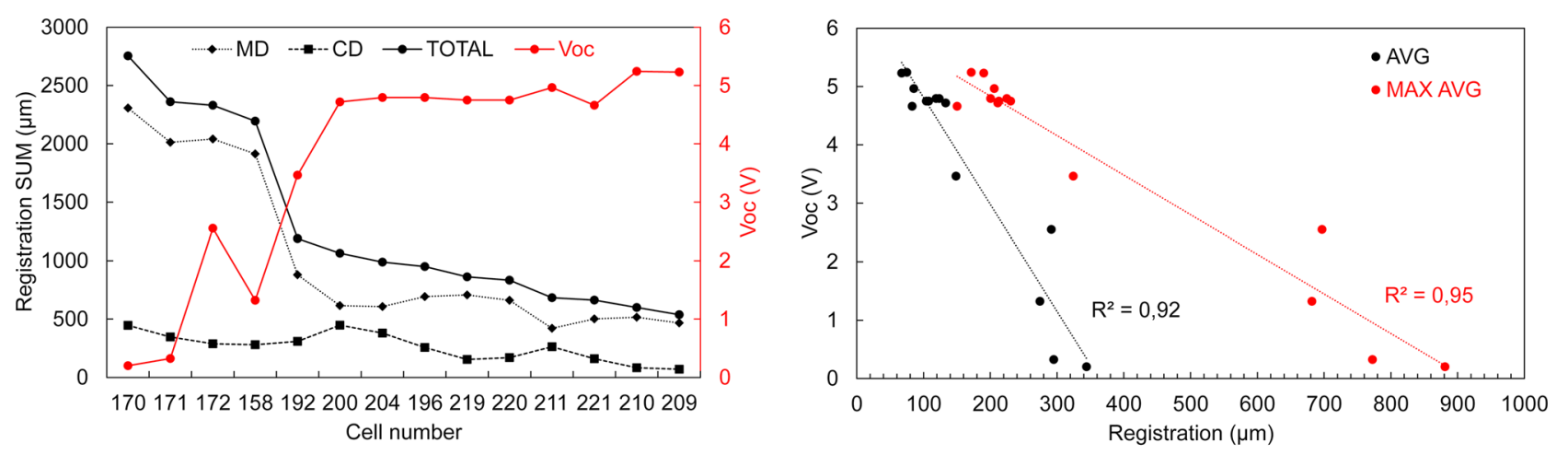

Fig. 11 Effect of the registration accuracy on the OPV performance (Voc). The sum of registration errors of each printed layer (left) as well as the Voc of a Calligraphy modules (10 cells in series) as a function of average registration and maximum registration errors (right) are presented

a.)

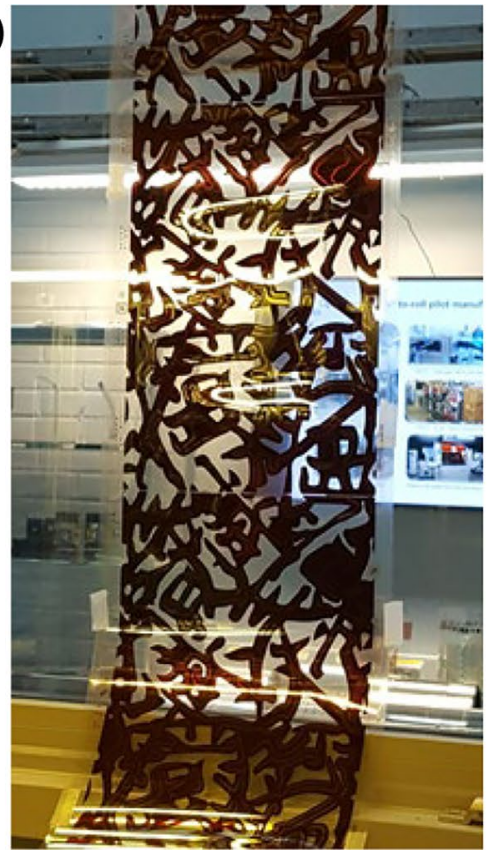

b.)

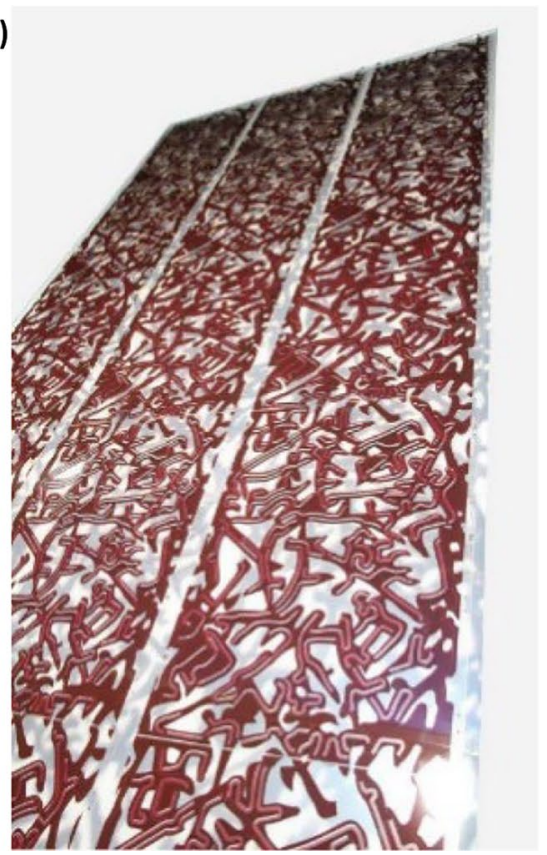

c.)

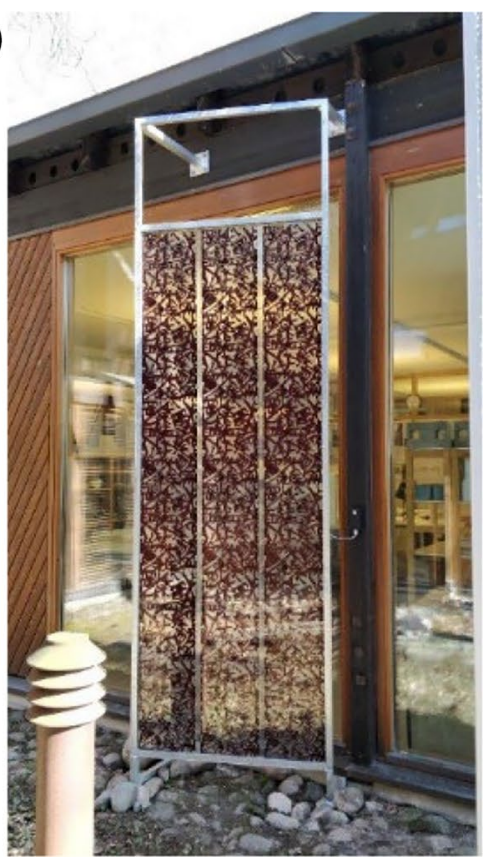

Fig. 12 R2R printed free-form a) OPV Calligraphy film, b) OPV Calligraphy encapsulated inside glass element and c) OPV Calligraphy in the façade of the building

\section{Conclusions}

This study has provided, for the first time, clear and detailed evidence for the necessity to thermally pre-treat PET substrates to increase dimensional stability when used for printed electronics manufacturing. The experimental results have proven this phenomenon for both roll-to-roll (R2R) and sheetto-sheet (S2S) processing with the following key findings:

1. Main dimensional changes of the heat stabilized PET film $(0.357 \% \mathrm{MD})$ will occur in the first R2R process- ing stage and not subsequent cycles $(0.002 \% \mathrm{MD})$ if the temperature and web tension are not increased.

2. In the $\mathrm{S} 2 \mathrm{~S}$ process, the dimensional changes of the heat stabilized PET film reduced from $-0.097 \%$ (MD) and $-0.134 \%$ (TD) to $0.024 \%$ (MD) and $-0.013 \%$ (TD) after the first processing stage while unstrained.

3. The pre-treatment improves average $\mathrm{S} 2 \mathrm{~S}$ registration accuracy by $40 \%$ and decreases MAX-MIN registration values to $33-43 \%$. The registration accuracy is slightly reduced in $\mathrm{R} 2 \mathrm{R}$ processing as the web tension plays a role in the substrate stabilization. 
4. Optical and mechanical performance of the PET film did not diminish with the R2R pre-treatment.

5. Printed free-form OPV designs reached the electrical properties similar to the reference design when the registration error of the deposited layer was 300-400 $\mu \mathrm{m}$. Furthermore, MAX-MIN error and a sum of registration errors are important to take into account when designing devices.

6. The thermal pre-treatment stabilizes the substrate dimensions before the printing and improves the layer-to-layer registration accuracy in printed electronic devices. Without pre-treatment, the substrate dimensional stability contributes to the registration errors to a degree similar to the printing registration inaccuracy, whereas after pre-treatment, the error caused by substrate stability is negligible compared to the print unit error. Highperformance printed electronic device designs must include dimensional tolerance of the substrate deformation and printing methods (press/techniques) for all steps of the fabrication process (environmental exposure and applied forces). Furthermore, as we remove the dimensional error caused by the substrate stability, the precision of the printing primarily relies upon the resolution of the printing techniques and registration systems.

To elaborate the importance of these findings, dimensional changes during processing can be problematic for manufacturers if there are a series of stages which involve heating under tension. If all processing stages are at the same temperature and tension, then the (majority of) dimensional change will occur only in the first processing stage and the first processing cycle can be used for the substrate pre-treatment. In other words, the length of the film under tension at ambient temperature before and after each stage will change significantly only through the first processing station $(0.357 \%$ in $\mathrm{MD})$, and not subsequent ones $(0.002 \%$ in $\mathrm{MD})$, as demonstrated in the findings of this study. The improved stability comes from establishing a new level of the strain in the crystalline PET film structure and freezing it in at the tensions and temperatures it is exposed to. Once this has happened, further changes in dimensional stability are limited when exposed again to identical conditions as the right level of strain (shrinkage force) will prevent change (stretch). The layer-to-layer alignment accuracy plays an important role in the printed electronics by affecting the performance and functionality of the multilayer devices.

In a R2R printing process with an automatic registration system, the registration fluctuates slightly (close to the optimal registration) resulting in minute variations in the process. The fluctuations are typically larger in MD than in TD because of the larger variations and oscillations in the web tension and printing press taking place in the printing direction. The printing method and printing speed affect the registration accuracy, and it should be taken into account when designing multilayer devices. The printed layers should be able to misalign themselves in every direction within the limits of the registration system of the used printing press without affecting the device performance. R2R printing machine with MAXI and its automated registration system shows that each deposited layer should be able to misalign by $300-400 \mu \mathrm{m}$ without affecting the device performance. Notably, the MIN-MAX registration errors and a sum of registration errors are important values to take into account. The thermal pre-treatment of the substrate can improve the registration accuracy further by $40 \%$ by stabilizing the substrate dimensions. The S2S treatment above the glass transition temperature ( $\mathrm{Tg}$ ) of the substrate stabilizes the substrate dimensions by relaxing the polymer chains and residual strains within the plastic films. Therefore, any biaxial shrinkage or expansion of the plastic substrate sheet should take place during the preliminary S2S cycle, thus giving a dimensionally stabilized substrate for multilayer printing and thermal annealing. This is important for electronic devices that pattern by printing (i.e. gravure, screen, flexographic) all R2R and S2S deposited thin film layers providing incredible flexibility for design freedom. The R2R fabrication of OPVs shows the printed free-form shapes in the form of Santa Claus, Camouflage and Triangle obtained functionality that was comparable with the reference, Rectangleshaped module design.

Supplementary information The online version contains supplementary material available at https://doi.org/10.1007/s00170-022-08717-z.

Acknowledgements The authors want to acknowledge Harmen Rooms from Coatema Coating Machinery $\mathrm{GmbH}$ for valuable comments, Professor Pekka Salminen and Jarkko Salminen from PES Architects Ltd., for providing the Calligraphy design, Dr. Pälvi Apilo, Dr. Marja Vilkman and Tapio Ritvonen for valuable contribution in R2R printing of organic photovoltaics, Tuomas Kokko for helping with R2R data management, and Jenni Tomperi, Anne Peltoniemi and Marven Mansour for excellent technical assistance and Antti Veijola for the photographs.

Funding Open Access funding provided by Technical Research Centre of Finland (VTT). This research received funding through the OLEDSOLAR project (European Union's Horizon 2020 research and innovation programme under grant agreement No. 820789) and the Academy of Finland Flagship Programme, Photonics Research and Innovation (PREIN), decision 320168. Part of the facilities used were provided by the Academy of Finland Research Infrastructure "Printed Intelligence Infrastructure" (PII-FIRI, grant no. 320020).

Availability of data and material The authors confirm that the data supporting the findings of this study are available in this manuscript and/ or its supplementary information document. The raw data that support the findings of this study are available from the corresponding author upon a reasonable request. 


\section{Declarations}

Ethical approval This manuscript does not contain any studies with human participants or animals.

Consent to participate All authors provided their consent.

Consent for publication All authors have read and agreed to publish this manuscript.

Competing interests The authors declare no competing interests.

Open Access This article is licensed under a Creative Commons Attribution 4.0 International License, which permits use, sharing, adaptation, distribution and reproduction in any medium or format, as long as you give appropriate credit to the original author(s) and the source, provide a link to the Creative Commons licence, and indicate if changes were made. The images or other third party material in this article are included in the article's Creative Commons licence, unless indicated otherwise in a credit line to the material. If material is not included in the article's Creative Commons licence and your intended use is not permitted by statutory regulation or exceeds the permitted use, you will need to obtain permission directly from the copyright holder. To view a copy of this licence, visit http://creativecommons.org/licenses/by/4.0/.

\section{References}

1. Khan Y, Thielens A, Muin S, Ting J, Baumbauer C, Arias AC (2020) A new frontier of printed electronics: flexible hybrid electronics. Adv Mater 32(15):1905279. https://doi.org/10.1002/adma.201905279

2. Välimäki M, Apilo P, Po R, Jansson E, Bernardi A, Ylikunnari M, Vilkman M, Corso G, Puustinen J, Tuominen J, Hast J (2015) R2Rprinted inverted OPV modules-towards arbitrary patterned designs. Nanoscale 7(21):9570-9580. https://doi.org/10.1039/C5NR00204D

3. Välimäki M, Jansson E, Korhonen P, Peltoniemi A, Rousu S (2017) Custom-shaped organic photovoltaic modules-freedom of design by printing. Nanoscale Res Lett 12(1):1-7. https://doi.org/10.1186/ s11671-017-1871-9

4. Kim YY, Yang TY, Suhonen R, Välimäki M, Maaninen T, Kemppainen A, Jeon NJ, Seo J (2019) Gravure-printed flexible perovskite solar cells: toward roll-to-roll manufacturing. Adv Sci 6(7):1802094. https://doi.org/10.1002/advs.201802094

5. Pettersson F, Keskinen J, Remonen T, Von Hertzen L, Jansson E, Tappura K, Zhang Y, Wilén CE, Österbacka R (2014) Printed environmentally friendly supercapacitors with ionic liquid electrolytes on paper. J Power Sources 271:298-304. https://doi.org/10.1016/j. jpowsour.2014.08.020

6. Vilkman M, Hassinen T, Keränen M, Pretot R, Van Der Schaaf P, Ruotsalainen T, Sandberg HG (2015) Fully roll-to-roll processed organic top gate transistors using a printable etchant for bottom electrode patterning. Org Electron 20:8-14. https://doi.org/10. 1016/j.orgel.2015.01.031

7. Park J, Lee J, Park S, Shin KH, Lee D (2016) Development of hybrid process for double-side flexible printed circuit boards using roll-toroll gravure printing, via-hole printing, and electroless plating. Int J Adv Manuf Technol. 82(9-12):1921-31. https://doi.org/10.1007/ s00170-015-7507-2

8. Kujala M, Kololuoma T, Keskinen J, Lupo D, Mäntysalo M, Kraft TM (2020) Bending reliability of screen-printed vias for a flexible energy module. npj Flex Electron 4(1):1-8. https://doi.org/ $10.1038 / \mathrm{s} 41528-020-00087-4$
9. Keränen K, Korhonen P, Rekilä J, Tapaninen O, Happonen T, Makkonen P, Rönkä K (2015) Roll-to-roll printed and assembled large area LED lighting element. Int J Adv Manuf Technol. 81(1):529_ 536. https://doi.org/10.1007/s00170-015-7244-6

10. Juntunen E, Ihme S, Huttunen A, Mäkinen JT (2017) R2R process for integrating LEDs on flexible substrate, in 2017 IMAPS Nordic Conference on Microelectronics Packaging (NordPac) 2017 Jun 18 (pp 12-16). IEEE. https://doi.org/10.1109/NORDPAC.2017.7993155

11. Jansson E, Korhonen A, Hietala M, Kololuoma T (2020) Development of a full roll-to-roll manufacturing process of through-substrate vias with stretchable substrates enabling double-sided wearable electronics. Int J Adv Manuf Technol. 111(11):3017-3027. https://doi. org/10.1007/s00170-020-06324-4

12. Khan S, Lorenzelli L, Dahiya RS (2015) Technologies for printing sensors and electronics over large flexible substrates: A review. IEEE Sens J. 15(6):3164-3185. https://doi.org/10.1109/JSEN.2014.2375203

13. Noh J, Jung M, Jung Y, Yeom C, Pyo M (2015) Cho G (2015) Key issues with printed flexible thin film transistors and their application in disposable RF Sensors. Proc IEEE 103(4):554-566. https://doi. org/10.1109/JPROC.2015.2410303

14. Kim CH (2012) You H Il, Lee SH (2012) Register control of roll-to-roll gravure-offset printing equipment considering time difference between measurement and actuation. Proc Inst Mech Eng C J Mech Eng Sci 226(11):2726-2738. https://doi.org/10.1177/0954406211433247

15. Seshadri A, Pagilla PR, Lynch JE (2013) Modeling print registration in roll-to-roll printing presses. J Dyn Syst Meas Control Trans ASME 135(3):031016. https://doi.org/10.1115/1.4023761

16. Lee E, Choi YM, Lee SH, Kwon S, Lee TM, Kang D (2017) Enhancement of printing overlay accuracy by reducing the effects of mark deformations. Microelectron Eng. 180:8-14. https://doi.org/ 10.1016/j.mee.2017.05.046

17. Salam B, Shan XC, Zhanhong C, Lok B (2018) Multilayer rollto-roll screen-printing for printed electronics applications, in 2018 IEEE 20th Electronics Packaging Technology Conference (EPTC) 2018 Dec 4 (359-362). IEEE. https://doi.org/10.1109/EPTC.2018. 8654393

18. MacDonald WA, Looney MK, MacKerron D, Eveson R, Adam R, Hashimoto K, Rakos K (2007) Latest advances in substrates for flexible electronics. J Soc Inf Disp 15(12):1075-1083. https://doi. org/10.1889/1.2825093

19. Choi MC, Kim Y, Ha CS (2008) Polymers for flexible displays: From material selection to device applications. Prog Polym Sci 33(6):581-630. https://doi.org/10.1016/j.progpolymsci.2007.11.004

20. Feig VR, Tran H, Bao Z (2018) Biodegradable Polymeric Materials in Degradable Electronic Devices. ACS Cent Sci 4(3):337-48. https://doi.org/10.1021/acscentsci.7b00595

21. Hast J, Jansson E, Suhonen R, Hakola L, Tuomikoski M, Vilkman M, Rönkä K, Kopola H (2017) Printed Electronics Solutions-Based Processes with Flexible Glass. In: Garner SM (ed) Flexible Glass: Enabling Thin, Lightweight and Flexible Electronics, 1st edn. Wiley, pp 181-210

22. Ni H, Liu J, Wang Z, Yang S (2015) A review on colorless and optically transparent polyimide films: Chemistry, process and engineering applications. J Ind Eng Chem 28:16-27. https://doi.org/10. 1016/j.jiec.2015.03.013

23. Heffelfinger CJ (1969) Biaxially oriented heat set film of high molecular weight polyethylene terephthalate. U.S. Patent No. 3432591

24. Gohil RM (1994) Morphology-property relationship in oriented PET films: Microstructural reorganization during heat treatment. J Appl Polym Sci 52(7):925-944. https://doi.org/10.1002/app.1994. 070520711

25. DuPontTeijinFilms, MELINEX® ST506 datasheet, https://usa. dupontteijinfilms.com/wp-content/uploads/2017/01/ST506-Datas heet.pdf. Accessed 2 Nov 2021 
26. MacDonald WA (2004) Engineered films for display technologies. J Mater Chem 14(1):4-10. https://doi.org/10.1039/B310846P

27. JEDEC, JESD22-A101D standard, Steady-state temperature-humidity bias life test, https://www.jedec.org/standards-documents/docs/ jesd-22-a101c. Accessed 2 Nov 2021

28. IEC, IEC 60068-2-78:2012 standard, Environmental testing - Part 2-78: Tests - test cab: damp heat, steady state, https://webstore.iec. ch/publication/560. Accessed 2 Nov 2021

29. Hassan MK, Cakmak M (2015) Strain-Induced Crystallization during Relaxation Following Biaxial Stretching of PET Films: A RealTime Mechano-Optical Study. Macromolecules 48(13):4657-4668. https://doi.org/10.1021/acs.macromol.5b00388

30. Vishnu Subramaniam S, van der Wiel B, Sauermann T, Kutsarov D, Schilinsky P, Pätzold R, Baumann RR, Meier SB (2020) Late-stage customization in volume production of organic photovoltaics. ACS
Appl Electron Mater 2(3):756-762. https://doi.org/10.1021/acsae $\operatorname{lm} .9 \mathrm{~b} 00826$

31. Välimäki M, Väisänen K-L, Ylikunnari M, Kemppainen A (2019) Organic photovoltaics for building façades, in 2019 10th International Conference on Flexible and Printed Electronics (ICFPE) 2019 Oct 23 (22)

32. Apilo P, Välimäki M, Po R, Väisänen K-L, Richter H, Ylikunnari M, Vilkman M, Bernardi A, Corso G, Hoppe H, Roesch R (2018) Fully roll-to-roll printed $\mathrm{p} 3 \mathrm{ht} /$ indene-c60-bisadduct modules with high open-circuit voltage and efficiency. Sol RRL 2(3):1700160. https://doi.org/10.1002/solr.201700160

Publisher's Note Springer Nature remains neutral with regard to jurisdictional claims in published maps and institutional affiliations. 